\title{
A Genome-Wide Analysis of the Chloroplast NADH Dehydrogenase-like Complex in Zostera Marina: Identification, Splicing, Editing and Profiles of Expression
}

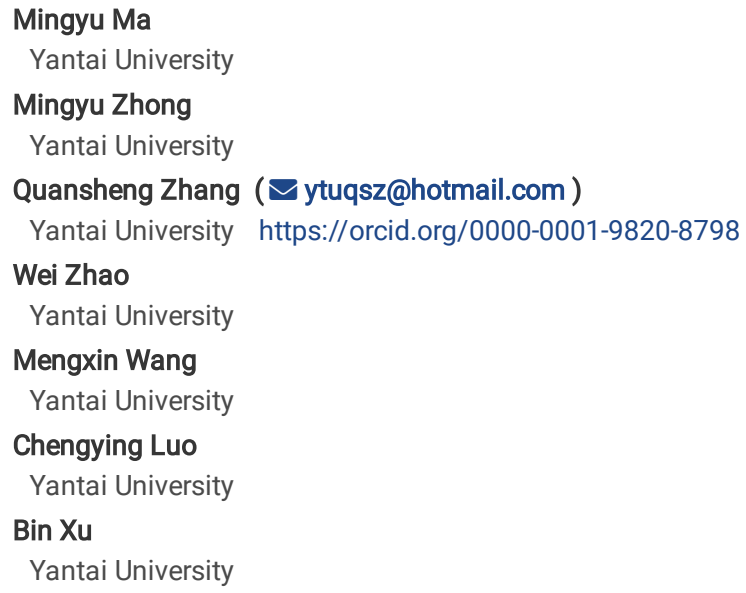




\section{Abstract}

Background: The chloroplast NADH dehydrogenase-like (NDH) complex, homologous to respiratory complex I, participates in photosystem I cyclic electron flow (PSI-CEF) and chlororespiration in photosynthesis. However, little information was available about the ndh genes in Zostera marina which is one of the most productive and wide-distributed seagrasses.

Results: The phylogenetic analysis indicated that Z. marina has a complete NDH complex which is rarely observed in marine macrophytes. We identified all 31 $n d h$ genes necessary for the functional NDH complex, with $n d h B$ and pnsb3 occurring as duplication events. Secondary structural analyses of antiporter-like subunits showed that the long amphipathic helix of NdhF was lost in Z. marina, suggesting an alternative mode in the generation of trans-thylakoid proton gradient. The splicing pattern in $n d h$ genes exhibited tissue-specific patterns but no response to photo-regulation. RNA editing in $Z$. marina presented the ancestral pattern with many of the primitive editing sites and types. The partial editing in $n d h F$ reflected the link between light stress and RNA editing. Moreover, predominant expression in the leaves of most $n d h$ genes implied their major function in photosynthesis. The dynamic profiles of expression in response to light stress suggested that there were two diverse responsive and regulatory mechanisms of the NDH complex in PSI-CEF and chlororespiration.

Conclusions: In this study, we performed a systematic analysis of the identification, splicing, editing and pattern of expression of the Z. marina NDH complex. Our study help elucidate the further evolutionary and functional exploration of the NDH complex.

\section{Background}

The chloroplast NADH dehydrogenase-like (NDH) complex is one of the thylakoid membrane protein complexes that participates in photosynthetic electron transport chains. The NDH complex catalyzes the transfer of electrons from ferredoxin (Fd) to plastoquinone resulting in translocation of protons from the stroma to lumen across the thylakoid membrane. This process leads to the generation of trans-thylakoid proton gradient, which drives the production of ATP $[1,2]$. Cyanobacterial NDH-1 can be divided into two major parts that contain the membrane segments (NdhA-NdhG) that participate in proton translocation and the peripheral segments (NdhH-NdhK) that carry redox centers, Fe-S clusters and flavin mononucleotide. The two parts form the L-shape structure which is conserved in both photosynthetic and respiratory NDH complexes [3-6]. Additionally, some new subunits that are required to stabilize the NDH complex in higher plants were found. Thus, the complete structure of the chloroplast NDH complex is composed of five subcomplexes, including subcomplex $\mathrm{M}$ (NdhANdhG), subcomplex A (NdhH-NdhO), subcomplex B (PnsB1-PnsB5), subcomplex L (PnsL1-PnsL5) and subcomplex EDB (NdhS-NdhV) [7].

Since the defective $n d h B$ gene was found to influence photosystem I cyclic electron transport (PSI-CEF) in Synechocystis sp. PCC 6803 [8], substantial evidence indicates that chloroplast NDH is involved in PSI-CEF and chlororespiration $[1,2,9]$. Although NDH-dependent PSI-CEF subtly contributes to the total PSI-CEF under optimal growth conditions, the chloroplast NDH complex plays essential roles in the regulation of plant tolerance to abiotic stress. For example, the chloroplast NDH complex functions to alleviate the oxidative stress caused by heat, low irradiance, humidity, high light stress, and so on [10-17]. It also functions in the regulation of proton motive force at low light intensity and temperature [18]. Moreover, NDH-dependent PSI-CEF is necessary for the normal growth of plants [19]. Additionally, based on the fact that the 11 plastid-encoded Ndh subunits (NdhA-NdhK) are homologous to their counterparts in the mitochondrial NADH dehydrogenase [20,21], the chloroplast NDH complex has been experimentally demonstrated to couple with the plastid terminal plastoquinone oxidase to mediate respiratory electron transport in chloroplasts which is referred to chlororespiration [22].

A general consensus is that the chloroplast NDH complex originated from the cyanobacterial NDH-1 complex [23]. To enhance the turnover of the electron flux via $\mathrm{Fd}$ and effectively resist stress, the NDH complex has attained dozens of novel subunits during the evolution of land plants [19]. Subcomplex M and several subunits in Subcomplex A (NdhH-NdhK), which forms the skeleton of NDH complex, are highly conserved in Escherichia coli., cyanobacteria and land plants [3]. Subcomplex B, which participates in the maintenance of the complex stability, emerged during the early stage of evolution of land plants [24]. Marchantia polymorpha, which is considered to be the earliest case of divergence from the land plant lineage, merely contains a portion of Subcomplex L [25], indicating this subcomplex is unique to terrestrial higher plants. NdhS in combination with NdhV in Subcomplex EDB form the Fd-binding site and is conserved in cyanobacteria and terrestrial higher plants, while other subunits in Subcomplex EDB are specific to terrestrial higher plants [26-28]. The integral chloroplast NDH complex primarily found in terrestrial higher plants, although some species in the Orchidaceae, Pinaceae, Gnetaceae and Geraniaceae have lost their chloroplast NDH complex during evolution [29-32]. The reason for the drastic variation in evolution of chloroplast NDH complex still remains unclear.

Zostera marina (Alismatales: Zosteraceae), one of the most productive species of seagrass, is widely distributed in the northern Pacific and northern Atlantic Oceans [33]. As the main component of seagrass meadows, it has crucial ecological values in nutrient cycling and sediment stabilization, as well as the provision of habitats and food provision for numerous organisms [34]. Seagrasses migrated to terrestrial conditions approximately 200 million years ago and returned to the sea approximately 140 million years ago [35]. During the migration to ocean, Z. marina occurred numerous gene losses and gains. Additionally, it evolved many unique structural and physiological characters to completely adapt to the marine environment. In this study, all $31 \mathrm{ndh}$ genes of the entire $\mathrm{NDH}$ complex were identified in Z. marina, although they have rarely been detected in marine macrophytes even among the seagrasses in Alismatales [36]. Correspondingly, our previous research suggested that Z. marina possesses a highly efficient NDH-dependent PSI-CEF and chlororespiration [15, 37]. Although the structure, physiological function and assembly of chloroplast NDH has been reported in other species [19, 38], the specifically-evolved and highly efficient Z. marina NDH has yet remained to be investigated to our knowledge. The whole genome sequences that have been reported enabled us to conduct a systematic research of $n d h$ genes in $Z$. marina $[33,39]$. We comprehensively analyzed the phylogeny, gene structures, motif compositions, secondary structures, alternative splicing, RNA editing events, patterns of expression and upstream regulation of $n d h$ genes in $Z$. marina. The pattern of expression also provided clues to understand how ndh genes coordinate with each other to drive the highly efficient NDH-dependent PSI-CEF in response to light exposure and chlororespiration during the subsequent recovery from being subjected to darkness. 


\section{Results}

\section{Identification of the Ndh subunits}

A total of $31 \mathrm{Ndh}$ subunits homologous to their Arabidopsis thaliana counterparts were obtained from Z. marina (Fig. 1, Table 1). NdhB and PnsB3 occurred duplication events during evolution. The annotations of these subunits were validated using the available transcriptome data of $Z$. marina. Gene Zosma266g00030.1 encoding the NdhV subunit and Zosma266g00040.1 encoding a hypothetical protein were contained in one transcript (designated Zosma266g0003040.1). Following the confirmation by reverse transcription-PCR (RT-PCR) and sequencing, in silico translation revealed that Zosma266g0003040.1 translated a 191 amino acid while Zosma266g00030.1 translated a 189 aa-long protein, suggesting that Zosma266g00040.1 might be located in the 3' UTR region of Zosma266g0003040.1. Furthermore, the misannotated coding sequence of $n d h B$ was observed during the analysis of sequenced cDNA fragments in RNA editing. The duplicated $n d h B$ had a uniform coding sequence with a 509 amino acid. 
Table 1

Features of $n d h$ genes identified in Zostera marina

\begin{tabular}{|c|c|c|c|c|c|c|c|c|c|c|}
\hline Group & $\begin{array}{l}\text { Gene } \\
\text { Name }\end{array}$ & Gene ID & $\begin{array}{l}\text { Size } \\
\left(\mathrm{aa}^{1}\right)\end{array}$ & $\begin{array}{l}\text { MW } \\
\text { (Da) }\end{array}$ & pl & $\begin{array}{l}\text { Encoded } \\
\text { Location }\end{array}$ & $\begin{array}{l}\text { Chromosome } \\
\text { No. }\end{array}$ & $\begin{array}{l}\text { Gene } \\
\text { span }\end{array}$ & Strand & Domain Type \\
\hline \multirow[t]{8}{*}{$\begin{array}{l}\text { Subcomplex } \\
\text { M }\end{array}$} & $n d h A$ & CRD45_pgp012 & 366 & 41058 & 6.42 & Chloroplast & NC_036014.1 & $\begin{array}{l}113255- \\
115486\end{array}$ & - & NADHdh \\
\hline & $\begin{array}{l}n d h B- \\
1\end{array}$ & CRD45_pgp021 & 541 & 60531.28 & 5.69 & Chloroplast & NC_036014.1 & $\begin{array}{l}132775- \\
135002\end{array}$ & + & Proton_antipo_M \\
\hline & $\begin{array}{l}n d h B- \\
2\end{array}$ & CRD45_pgp006 & 476 & 53088.81 & 5.79 & Chloroplast & NC_036014.1 & $\begin{array}{l}92137- \\
94313\end{array}$ & - & Proton_antipo_M \\
\hline & $n d h C$ & CRD45_pgp058 & 120 & 13869.39 & 4.19 & Chloroplast & NC_036014.1 & $\begin{array}{l}49652- \\
50014\end{array}$ & - & Oxidored_q4 \\
\hline & $n d h D$ & CRD45_pgp017 & 495 & 55997.58 & 8.02 & Chloroplast & NC_036014.1 & $\begin{array}{l}108739- \\
110226\end{array}$ & - & Proton_antipo_M \\
\hline & $n d h E$ & CRD45_pgp015 & 101 & 11267.32 & 9.43 & Chloroplast & NC_036014.1 & $\begin{array}{l}111014- \\
111319\end{array}$ & - & Oxidored_q2 \\
\hline & $n d h F$ & CRD45_pgp009 & 627 & 71389.28 & 8.53 & Chloroplast & NC_036014.1 & $\begin{array}{l}118195- \\
120078\end{array}$ & + & Proton_antipo_M, \\
\hline & $n d h G$ & CRD45_pgp014 & 184 & 20539.59 & 5.01 & Chloroplast & NC_036014.1 & $\begin{array}{l}111617- \\
112171\end{array}$ & - & Oxidored_q3 \\
\hline \multirow[t]{8}{*}{$\begin{array}{l}\text { Subcomplex } \\
\text { A }\end{array}$} & $n d h H$ & CRD45_pgp011 & 404 & 47130.71 & 5.48 & Chloroplast & NC_036014.1 & $\begin{array}{l}115458- \\
116672\end{array}$ & - & Complex1_49 kDa \\
\hline & $n d h l$ & CRD45_pgp01 & 208 & 24405.6 & 8.77 & Chloroplast & NC_036014.1 & $\begin{array}{l}112589- \\
113215\end{array}$ & - & $\begin{array}{l}4 \mathrm{Fe}-4 \mathrm{~S} \text { ferredoxin- } \\
\text { type }\end{array}$ \\
\hline & $n d h J$ & CRD45_pgp060 & 164 & 19399.37 & 6.96 & Chloroplast & NC_036014.1 & $\begin{array}{l}48341- \\
48835\end{array}$ & - & Complex1_30 kDa \\
\hline & $n d h K$ & CRD45_pgp059 & 254 & 28713.9 & 9.07 & Chloroplast & NC_036014.1 & $\begin{array}{l}48918- \\
49682\end{array}$ & - & Oxidored_q6 \\
\hline & $n d h L$ & Zosma137g00200.1 & 178 & 20545.08 & 10.28 & Nuclear & scaffold_137 & $\begin{array}{l}166629- \\
167827\end{array}$ & + & NdhL \\
\hline & $n d h M$ & Zosma57g00680.1 & 195 & 22336.32 & 6.43 & Nuclear & scaffold_57 & $\begin{array}{l}643639- \\
644318\end{array}$ & + & NdhM \\
\hline & $n d h N$ & Zosma31g01120.1 & 213 & 23958.89 & 9.59 & Nuclear & scaffold_31 & $\begin{array}{l}691078- \\
692835\end{array}$ & - & $\mathrm{NdhN}$ \\
\hline & ndho & Zosma196g00030.1 & 151 & 17295.97 & 9.32 & Nuclear & scaffold_196 & $\begin{array}{l}14822- \\
15619\end{array}$ & - & NdhO \\
\hline \multirow{4}{*}{$\begin{array}{l}\text { Subcomplex } \\
\text { EDB }\end{array}$} & $n d h S$ & Zosma89g00850.1 & 250 & 27012.9 & 5.86 & Nuclear & scaffold_89 & $\begin{array}{l}385211- \\
385963\end{array}$ & + & NdhS \\
\hline & $n d h T$ & Zosma161g00490.1 & 246 & 28246.91 & 6.24 & Nuclear & scaffold_161 & $\begin{array}{l}203503- \\
204402\end{array}$ & - & DnaJ_domain \\
\hline & $n d h U$ & Zosma87g00270.1 & 218 & 24501.81 & 5.31 & Nuclear & scaffold_87 & $\begin{array}{l}167738- \\
172875\end{array}$ & - & DnaJ_domain \\
\hline & $n d h V$ & Zosma266g00030.1 & 189 & 20813.9 & 9.01 & Nuclear & scaffold_266 & $\begin{array}{l}58607- \\
59816\end{array}$ & + & Unkown \\
\hline \multirow[t]{6}{*}{$\begin{array}{l}\text { Subcomplex } \\
\text { B }\end{array}$} & pnsb1 & Zosma16g01560.1 & 468 & 51745.35 & 6.43 & Nuclear & scaffold_16 & $\begin{array}{l}985167- \\
987045\end{array}$ & + & Unkown \\
\hline & pnsb2 & Zosma39g00680.1 & 345 & 37684.75 & 6.97 & Nuclear & scaffold_39 & $\begin{array}{l}735514- \\
738322\end{array}$ & + & Unkown \\
\hline & ${\underset{1}{1}}_{\text {pnsb3- }}$ & Zosma5g02060.1 & 200 & 22198.17 & 8.82 & Nuclear & scaffold_5 & $\begin{array}{l}1067520- \\
1068382\end{array}$ & - & $\begin{array}{l}2 \mathrm{Fe}-2 \mathrm{~S} \text { ferredoxin- } \\
\text { type }\end{array}$ \\
\hline & $\begin{array}{l}\text { pnsb3- } \\
2\end{array}$ & Zosma74g01180.1 & 229 & 25810.87 & 9.72 & Nuclear & scaffold_74 & $\begin{array}{l}611531- \\
612956\end{array}$ & - & $\begin{array}{l}2 \mathrm{Fe}-2 \mathrm{~S} \text { ferredoxin- } \\
\text { type }\end{array}$ \\
\hline & pnsb4 & Zosma248g00070.1 & 197 & 22725.65 & 4.89 & Nuclear & scaffold_248 & $\begin{array}{l}19172- \\
20349\end{array}$ & + & Unkown \\
\hline & pnsb5 & Zosma13g00670.1 & 218 & 24800.02 & 5.16 & Nuclear & scaffold_13 & $\begin{array}{l}574318- \\
576258\end{array}$ & + & Unkown \\
\hline
\end{tabular}




\begin{tabular}{|c|c|c|c|c|c|c|c|c|c|c|}
\hline Group & $\begin{array}{l}\text { Gene } \\
\text { Name }\end{array}$ & Gene ID & $\begin{array}{l}\text { Size } \\
\left(\mathrm{aa}^{1}\right)\end{array}$ & $\begin{array}{l}\text { MW } \\
(\mathrm{Da})\end{array}$ & pl & $\begin{array}{l}\text { Encoded } \\
\text { Location }\end{array}$ & $\begin{array}{l}\text { Chromosome } \\
\text { No. }\end{array}$ & $\begin{array}{l}\text { Gene } \\
\text { span }\end{array}$ & Strand & Domain Type \\
\hline \multirow[t]{5}{*}{$\begin{array}{l}\text { Subcomplex } \\
\text { L }\end{array}$} & pns/1 & Zosma22g00960.1 & 233 & 26187.86 & 9.27 & Nuclear & scaffold_22 & $\begin{array}{l}705701- \\
707101\end{array}$ & + & PsbP \\
\hline & pns/2 & Zosma30G00320.1 & 186 & 20883.08 & 9.05 & Nuclear & scaffold_30 & $\begin{array}{l}171042- \\
171602\end{array}$ & + & PsbQ \\
\hline & pns/3 & Zosma19G01210.1 & 253 & 27865.71 & 5.47 & Nuclear & scaffold_19 & $\begin{array}{l}809801- \\
810173\end{array}$ & + & PsbQ \\
\hline & pns/4 & Zosma241G00220.1 & 213 & 22654.18 & 8.99 & Nuclear & scaffold_241 & $\begin{array}{l}129967- \\
131195\end{array}$ & + & FKBP_C \\
\hline & pns 15 & Zosma225G00240.1 & 249 & 26927.66 & 9.08 & Nuclear & scaffold_225 & $\begin{array}{l}229925- \\
234960\end{array}$ & - & Pro_isomerase \\
\hline
\end{tabular}

${ }^{1}$ aa, amino acid

Phylogenetic analysis of ndh genes

To investigate the evolutionary relationship among Viridiplantae NDH complexes, the amino acid sequences of 31 Ndh subunits were concatenated to construct a phylogenetic tree. As shown in Fig. 2, the phylogeny of NDH complex was almost consistent with the phylogeny of species. The complexity of $\mathrm{NDH}$ complex appeared to be increasing from algae to bryophytes to land higher plants with the exception of gymnosperms. Therefore, the most integrated $\mathrm{NDH}$ complex was mostly found in the terrestrial angiosperms with an obvious diversification between monocots and dicots. Unlike other marine species, $Z$. marina had a complete NDH complex, which indicated its particular evolutionary status.

The phylogenetic tree of the entire NDH complex was also compared with those constructed by individual Ndh subunits. The phylogenies of most Ndh subunits, including NdhA, NdhE, NdhF, NdhG, Ndhl, NdhJ, NdhN, NdhT, NdhU, PnsL1, PnsL2, PnsL3 and PnsL4, were consistent with the concatenated phylogeny (Additional file 1A), indicating that these individual subunits co-evolved with the NDH complex. NdhB, PnsB3, NdhM, NdhO, and NdhS of Z. marina were at the basal branches of angiosperms (Additional file 1B), indicating their earlier evolution status.

\section{Motif composition of the ndh gene}

The motifs composition of each Ndh subunit and details of the motifs in conserved domain are shown in Additional file 1 and 2, respectively. The results revealed that closely related species usually shared a similar motif composition. The motifs in conserved domain were widely distributed, while the motifs in the $\mathrm{N}$ - and $\mathrm{C}$-terminal regions varied, particularly for nuclear-encoded Ndh subunits. Certain motifs are clearly unique to the $Z$. marina $\mathrm{Ndh}$ subunits, i.e., motif 20 in NdhG, motif 13 in NdhH and motif 14 in Ndhl, whereas certain conserved motifs were absent, i.e., motif 11 in NdhD and motifs 7, 14 and 17 in NdhF (Fig. 3). It was worth noting that the lost motifs in NdhD and NdhF were either located in the functional domain of the subunits or predicted to be a transmembrane helix.

Given the distinguishing motif composition of Z. marina in the functional domain of NdhD and NdhF, known as antiporter-like subunits, the multiple sequences of these subunits were aligned in six representative species of angiosperms. As shown in Fig. 4, NdhD harbors fourteen conserved TM helices, and NdhF harbors sixteen conserved TM helices. Unlike other species, Z. marina lost TM1 and TM13 in NdhD, which was ascribed to the substitution from motif 11 to 5 . Moreover, it lacked the long amphipathic helix in NdhF that was attributed to the absence of motifs 7, 14 and 17.

\section{The splicing pattern of ndh genes in different tissues and light stress}

The alternative splicing (AS) types of the $n d h$ genes that contained introns, including the chloroplast-encoded genes ( $n d h A, n d h B)$ and most of the nuclearencoded genes (with the exception of $n d h S$ and pns/2), were analyzed using RT-PCR (Fig. 5 and Additional file 3). Ten $n d h$ genes ( $n d h B, n d h L, n d h M, n d h U$, $n d h V$, pns/1, pns/4, pnsb2, pnsb3-1 and pnsb3-2) showed tissue-specific AS patterns (Fig. 5A), indicating that the AS of ndh genes possibly participated in the regulation of functional specification in different tissues. Remarkably, the AS transcripts of $n d h B(n d h B-A S-2)$ that consisted of exons 1 and 2 and intron 1 exhibited opposite pattern of expression with the fundamental transcript ( $n d h B-1$ ). Transcript of $n d h B-A S-2$ were the primary isoform in stems and rhizomes, while $n d h B-1$ was preferentially expressed in leaves. However, the AS transcripts in the ten genes described above did not response to the exposure of light according to the analysis of AS events in different light treatments (Fig. 5B). Subsequently, the gene structures of different transcript isoforms and their influence on protein translation were analyzed. As shown in Fig. 6, the AS transcripts either led to functionally impaired (ndhB-AS-2, ndhL-2, ndhM-2, ndhU-2, 3 and 4, ndhV-2, pnsb2-2, pnsb3-2-2 and 3, pnsb5-2, pns/1-2, 3 and 4), or untranslated mRNAs (ndhL-3 and psnb3-1-2).

\section{RNA editing analysis of the chloroplast-encoded ndh genes}

As shown in Table 2, a total of 35 editing sites were detected in eleven plastid-encoded $n d h$ genes, with partial editing of $n d h D$ and $n d h F$ and a lack of editing for $n d h C$. Compared with other species, $Z$. marina possessed more editing sites than those in Spirodela polyrhiza (the close relative of the seagrass), $A$. thaliana (the model dicot) and Zea mays (the model monocot) but fewer than those in $A$. trichopoda (the basal angiosperm). $Z$. marina shared more editing sites with Amborella trichopoda (12) than with S. polyrhiza (10), A. thaliana (8) and Z. mays (6). Furthermore, more types of editing, including $\mathrm{C}$ to $\mathrm{U}$ (48.6\%), $\mathrm{U}$ to $\mathrm{C}(20 \%), \mathrm{A}$ to $\mathrm{G}(14.3 \%), \mathrm{G}$ to A (8.6\%), C to A $(5.7 \%)$ and $\mathrm{G}$ to $\mathrm{T}(2.8 \%)$, existed in $Z$. marina, while only the $\mathrm{C}$ to $\mathrm{U}$ editing existed in the other plants. Additionally, most of the editing events tended to occur in the third bases of codons which led to silent editing. The second bases of codons were also edited, which resulted in the alteration of identity of amino acids. The majority of non-synonymous editing events in Z. marina either restored evolutionarily conserved 
amino acid sequences, such as the methionine to isoleucine conversion of the $n d h B 72$ th codon, the isoleucine to methionine conversion of the $n d h D 435$ th codon and the asparagine to asparticacid conversion of the $n d h H 50$ th codon, or generated lineage-specific residues in $Z$. marina compared with $S$. polyrhiza, A. thaliana and Z. mays, i.e., the $n d h D 220$ th, $n d h / 45$ th and $n d h K 51$ th codons (Fig. 7A and B and Additional file 4 and 5).

Table 2

Comparison of identified RNA editing sites in $n d h$ genes of $Z$. marina with other species

\begin{tabular}{|c|c|c|c|c|c|c|c|c|}
\hline Gene & Codon position & Bases & Codon $^{1}$ & Amino acid change & $\mathrm{Sp}^{2}$ & $A t^{2}$ & $\mathrm{Zm}^{2}$ & $\mathrm{Am}^{2}$ \\
\hline \multirow[t]{3}{*}{$n d h A$} & 44 & $A-G$ & Auu-Guu & $\mathrm{I}-\mathrm{V}$ & - & - & - & - \\
\hline & 199 & $\mathrm{C}-\mathrm{U}$ & uCa-uUa & S-L & + & - & - & + \\
\hline & 323 & U-C & uaU-uaC & $Y-Y$ & - & - & - & - \\
\hline \multirow[t]{6}{*}{$n d h B$} & 72 & G-A & auG-auA & $M-I$ & - & - & - & - \\
\hline & 155 & $\mathrm{C}-\mathrm{U}$ & cCa-cUa & P-L & + & + & + & + \\
\hline & 195 & $\mathrm{C}-\mathrm{U}$ & Cau-Uau & $\mathrm{H}-\mathrm{Y}$ & + & + & + & + \\
\hline & 245 & $\mathrm{C}-\mathrm{U}$ & cCa-cUa & P-L & + & - & + & + \\
\hline & 276 & $\mathrm{C}-\mathrm{U}$ & uCa-uUA & S-L & + & + & + & + \\
\hline & 493 & $\mathrm{C}-\mathrm{U}$ & cCa-cUa & P-L & + & + & + & + \\
\hline \multirow[t]{10}{*}{$n d h D$} & 43 & U-C & acU-acC & $\mathrm{T}-\mathrm{T}$ & - & - & - & - \\
\hline & 50 & $\mathrm{C}-\mathrm{U}$ & uuC-uuU & F-F & - & - & - & - \\
\hline & 123 & $\mathrm{C}-\mathrm{U}$ & uCa-uUa & S-L & + & + & - & + \\
\hline & 220 & $\mathrm{C}-\mathrm{U}$ & uCa-uUa & S-L & - & - & - & + \\
\hline & 225 & $\mathrm{C}-\mathrm{U}$ & Cua-Uua & L-L & - & - & - & + \\
\hline & 259 & U-C & auU-auC & $H$ & - & - & - & - \\
\hline & 288 & $\mathrm{C}-\mathrm{U}$ & uCa-uUa & S-L & + & + & + & + \\
\hline & 346 & G-U & acG-acU & T-T & - & - & - & - \\
\hline & 393 & $\mathrm{C}-\mathrm{U}$ & uCu-uUu & S-F & + & - & - & - \\
\hline & 435 & $A-G$ & auA-auG & $\mathrm{I}-\mathrm{M}$ & - & - & - & - \\
\hline$n d h E$ & 43 & U-C & auU-auC & $H$ & - & - & - & - \\
\hline \multirow[t]{3}{*}{$n d h F$} & 254 & U-C & gcU-gcC & $A-A$ & - & - & - & - \\
\hline & 361 & C-A & uCu-uAu & $S-Y$ & - & - & - & - \\
\hline & 468 & C-A & gCa-gAa & $A-E$ & - & - & - & - \\
\hline$n d h G$ & 107 & $\mathrm{C}-\mathrm{U}$ & guC-guU & $V-V$ & - & - & - & - \\
\hline \multirow[t]{4}{*}{$n d h H$} & 50 & $A-G$ & Aau-Gau & $\mathrm{N}-\mathrm{D}$ & - & - & - & - \\
\hline & 53 & G-A & ccG-ccA & P-P & - & - & - & - \\
\hline & 224 & U-C & gaU-gaC & $D-D$ & - & - & - & - \\
\hline & 238 & $\mathrm{C}-\mathrm{U}$ & ucC-ucU & S-S & - & - & - & - \\
\hline \multirow[t]{3}{*}{$n d h I$} & 45 & G-A & auG-auA & $\mathrm{M}-\mathrm{I}$ & - & - & - & - \\
\hline & 47 & $C-U$ & acC-acU & $\mathrm{T}-\mathrm{T}$ & - & - & - & - \\
\hline & 146 & U-C & ucU-ucC & S-S & - & - & - & - \\
\hline$n d h J$ & 49 & $\mathrm{C}-\mathrm{U}$ & uCa-uUa & S-L & + & - & - & + \\
\hline \multirow[t]{3}{*}{$n d h K$} & 51 & $\mathrm{C}-\mathrm{U}$ & uCg-uUg & S-L & - & - & - & + \\
\hline & 99 & $A-G$ & agA-agG & $\mathrm{R}-\mathrm{R}$ & - & - & - & - \\
\hline & 234 & $A-G$ & gaA-gaG & E-E & - & - & - & - \\
\hline \multicolumn{9}{|c|}{${ }^{1}$ The bases affected by RNA editing are shown in upper case } \\
\hline
\end{tabular}


The RNA editing events in different illumination conditions were also detected in the $n d h$ genes of $Z$. marina. Interestingly, partial editing of the 361 th codon in $n d h F$ resulting in the incomplete serine to tyrosine conversion was observed in the dark adaptation period but subsequently disappeared in the light exposure and recovery periods (Fig. 7C and Additional file 5).

\section{Patterns of expression of the ndh genes in different tissues}

The expression of all $31 \mathrm{ndh}$ genes derived from the five major tissues of $Z$. marina were also investigated, with the level of expression of the $n d h B$ represented the sum of duplicated $n d h B$ owing to their consensus coding sequences. As revealed in Fig. 8, plastid-encoded genes ( $n d h A-n d h K)$ were preferentially expressed in leaves but barely expressed in roots and rhizomes. Moreover, nuclear-encoded genes exhibited various patterns of expression across the five tissues. Five genes ( $n d h L, n d h U, n d h S, p n s / 2$ and $p n s / 4)$ in the roots, six genes (pnsb1, pnsb2, pnsb3-1, pnsb4, pnsb5 and pns/1) in the flowers and seven genes ( $n d h M, n d h N, n d h O, n d h T, n d h V, p n s b 3-2$ and $p n s / 3)$ in the leaves exhibited relatively high transcript abundances, while pns/5 was constitutively expressed. It was notable that pnsb3-1 was highly expressed in flowers. In contrast, its duplicated sister ( $p n s b 3-2)$ was particularly abundant in leaves. Unlike the other $n d h$ genes, $p n s / 4$ and $n d h L$ showed different patterns of expression with their counterparts in $A$. thaliana (Additional file 6 ), suggesting their functional divergence in different species.

\section{Patterns of expression of the ndh genes across high light stress and dark recovery}

To analyze the dynamic expression of $n d h$ genes, the eleven undetectable ( $n d h A-K)$ and eight differentially expressed $n d h$ genes ( $n d h L, n d h M, n d h S, n d h T$, $n d h V$, pnsb3-1, pnsb3-2 and pns/5) in the available transcriptome were selected (Additional file 7). As shown in Fig. 9, four $n d h$ genes in conserved Subcomplex M ( $n d h A)$, Subcomplex A ( $n d h J$ and $n d h K)$ and Subcomplex EDB ( $n d h V)$ were rapidly induced and maintained a relatively high level of expression throughout their exposure to light. Moreover, three other genes in Subcomplex $\mathrm{M}$ ( $n d h C, n d h D$ and $n d h E)$, as well as the two genes in Subcomplex B ( $p n s b 3-2$ ) and Subcomplex $\mathrm{L}(p n s / 5)$ that existed exclusively in terrestrial plants, were up-regulated during the middle and late stage of light exposure. Furthermore, these genes were also up-regulated during subsequent dark recovery period. In contrast, $n d h B, n d h H, n d h l, n d h L, n d h M$ and $p n s b 3-1$ were repressed during light exposure and then significantly induced during the recovery period. The dynamic patterns of expression of the ndh genes indicated that there were two distinctive responsive and regulatory mechanisms of the NDH complex during the periods of light exposure and the subsequent dark recovery.

\section{Stress-related cis-elements in ndh genes promoters}

To explore the possible regulatory mechanism of the $Z$. marina ndh genes, related cis-elements were scanned. There were three types of cis-elements, as shown in Fig. 10. Different amounts of light-responsive elements, including Box4, G-box, the GATA, GT1 and TCT motifs, were present in each ndh gene, with the G-box comprising the most abundant element. Among the $31 \mathrm{ndh}$ genes, pns/5 and $n d h M$ had more light responsive elements. The second type of ciselements were related to hormones, including those responsive to salicylic acid-, abscisic acid- and auxin, which were detected among 11 genes ( $n d h A, n d h G$, $n d h l, n d h M, n d h O, n d h S, p n s b 1, p n s b 2, p n s b 3-2, p n s b 5$ and pns/4). In addition, defense- and stress-responsive and WUN-motif and TC-rich repeats associated with wound responses were identified in nine genes $(n d h F, n d h H, n d h l, n d h M, n d h U, p n s b 3-2, p n s / 1, p n s / 2$ and pns/5). These results indicated that the $n d h$ genes can be regulated by numerous factors with light serving as the primary factor.

\section{Discussion}

The loss of $n d h$ genes was universal in marine macrophytes $[40,41]$, which was consistent with that the complexity of NDH gradually increased during the transition of marine plants to land plants. Considering that most of the $n d h$ mutants resulted in impaired NDH activity [42-46], it could be hypothesized that each Ndh subunit was indispensable, functioning either in the stability or the assembly of the NDH complex. Z. marina, as a marine seagrass, possessed a complete NDH that could possibly have been retained during the migration from land to sea. This phenomenon, taken in combination with the observations that NDH complex was prominently activated in light exposure and dark recovery examined in our previously studies [15, 37], suggested that the $Z$. marina $\mathrm{NDH}$ complex could have played a crucial role both in PSI-CEF and chlororespiration.

The comparison of the phylogeny between individual Ndh subunits and the entire NDH complex revealed that some genes had been vertically or horizontally transferred among Viridiplantae together with the entire NDH complex, although some ndh genes evolved independently. The earlier diversification of NdhM, $\mathrm{NdhO}$ and NdhS suggests a possible more primitive evolutionary status of these subunits in Z. marina.

Among the 31 ndh genes, two gene pairs ( $n d h B-1$ and $n d h B-2$, chloroplast genome encoded; pnsb3-1 and pnsb3-2, nuclear genome encoded) probably originated from gene duplication events. It is commonly accepted that the majority of gene duplications in chloroplast genomes are caused by the expansion of large inverted repeat regions (IRs) [47]. In this study, only a single $n d h B$ could be observed in the outgroup species, while the duplicated $n d h B$ paralogs in Cycas (the most ancient extant plants) and the angiosperms were all located on the chloroplast IRs [39, 48], which implied that the duplication of ndhB might emerge in the common ancestors of seed plants through the expansion of IRs. However, the phenomenon that some gymnosperms (Ginkgoaceae and Pinaceae) also possessed a single copy of $n d h B$ [49] could be attributed to the loss or contraction of IRs. In the case of nuclear encoded $p n s b 3$ paralogs, the duplication mode was identified at the Plant Duplicate Gene Database (PlantDGD, http://pdgd.njau.edu.cn:8080) as "single gene transposition-duplication" [50]. This mode of duplication, prevalent in plant genomes, generated two gene copies that are neither neighboring nor colinear. The non-duplicated pnsb3 in algae, bryophytes, lycophytes and gymnosperms, together with the independent orthologous groups of the duplicated pnsb3 (pnsb3-1 and pnsb3-2) in the monocots and dicots, indicated that the duplication events happened after the divergence of gymnosperms and angiosperms but before the divergence of monocots and dicots. In Z. marina, both paralogs possessed the core angiosperm motifs 1, 2, 3 and 4, while the additional motifs 5 , 10 and 15 were specific to pnsb3-1. The divergent motif composition combined with the different tissue-specific pattern of expression observed in our study suggested that the neofunctionalization and/or sub-functionalization of pnsb3 paralogs could help plants to adapt better to the dynamic and fluctuating environment [51]. 
Motifs in the functional domains were stringently conserved in most of the Z. marina Ndh subunits with the exception of NdhD and NdhF. Previous studies showed that a near-continuous long amphipathic a-helix between the 15th and 16th TM helices of NdhF were connected to other antiporter-like subunits [3]. This connection could transmit conformational changes in the hydrophilic domain of NDH, resulting in proton translocation. Thus, the absence of a TM helix in the N-terminus of $\mathrm{NdhD}$ and the loss of the long helix NdhF implied a possible modified mechanism for proton transmission in Z. marina. Moreover, the nonphotochemical quenching value, which depends on the $\mathrm{pH}$ gradient generated in the thylakoid, was at a low level in most of the seagrass species [52]. Thus, it was possible that the special proton transmission mechanism was related to the low non-photochemical quenching capacity.

AS, as a post-transcriptional regulatory mechanism, could generate diverse transcripts and played crucial roles in plant development and the resistance to different biotic and abiotic stresses [53-56]. In this study, many AS transcripts were predominantly observed in leaves that primarily contained chloroplasts. Clearly, the AS events in $n d h$ genes primarily participated in photosynthetic-related regulation. Many splice variants generate small interfering peptides that participated in the formation of multi-protein complex but lacked functional domain to compete with functional complex [53, 57]. Intriguingly, the AS transcripts of both $n d h B$ and pnsb2, which produced a truncated protein without functional domain, exhibited opposite patterns of expression with their fundamental transcripts, indicating a dominant-negative regulation of the AS events in these $n d h$ genes. As for light treatments, the AS events of $n d h$ genes displayed analogous splicing patterns across light exposure and the subsequent recovery, implying that the AS events of $n d h$ genes were not sensitive to light exposure.

RNA editing, another post-transcriptional process, resulted in numerous base transitions [58]. In addition, the canonical $\mathrm{C}$ to $\mathrm{U}$ editing and the abundant uncanonical $\mathrm{U}$ to $\mathrm{C}, \mathrm{A}$ to $\mathrm{G}$ and $\mathrm{G}$ to $\mathrm{A}$ conversions that had been reported to exist exclusively in ancestral land plants $[58,59]$ were unexpectedly present in $Z$. marina. Moreover, the minor $\mathrm{G}$ to $\mathrm{T}$ and $\mathrm{C}$ to $\mathrm{A}$ editing events which had never been reported in other plant species were detected. It is possible that $Z$. marina retained numerous ancestral editing patterns that had a monophyletic origin but were followed by lineage-specific losses and gains. As suggested by Jobson et al., (2008) the RNA editing events could change the protein structure or interaction through the non-synonymous replacement of conserved amino acids [60, 61]. Therefore, the editing events adjacent to the charged lysine residue in the TM7 helix of NdhD which was crucial for energy transduction [3], as well as in the second helix of NdhK and the N-terminal amphiphilic helix of Ndhl which had an impact on quinone-binding [5], could influence the functional NDH in $Z$. marina.

The incomplete conversion from serine to tyrosine in NdhF caused by the partial C to A editing was detected exclusively during the period of dark adaptation. The 361th serine found in the NdhF TM11 helix was conserved among most of the green plants. Accordingly, the partial non-synonymous editing of this codon was likely to alter the NdhF functions in NDH complex. It could be explained that, during the dark adaption, the partial 361 th serine to tyrosine conversion could inhibit the NDH activity because there was no need to establish powerful NDH functions. During the subsequent light exposure and dark recovery, the partial editing disappeared and integrated NDH molecules were then rebuilt to address the light stress through CEF-PSI and photorespiration. The whole process could be viewed as a post-transcriptional regulation of the functions of NDH complex in response to light exposure in $Z$. marina.

Similar to $A$. thaliana, most of the $n d h$ genes in Z. marina were primarily expressed in leaves, which implied the conserved function in photosynthesis of NDH complex during evolution. However, the prolyl cis/trans isomerase pns/4 and pns/5 exhibited a high level of expression in root and constitutive expression, respectively. The prolyl cis/trans isomerase could be involved in various physiological processes in addition to the assembly of NDH complex [62], such as hormone-mediated plant development and brassinosteroid-mediated flowering [63, 64], thereby leading to the unbiased expression in leaves. Additionally, the $n d h L$ in Z. marina was predominantly expressed in roots and flowers, which differed from that in $A$. thaliana. Enriched bicarbonate in seawater can be converted to $\mathrm{CO}_{2}$ in the surface of leaves to support the concentration of limited inorganic carbon (Ci) in fully marine conditions [65]. Therefore, the high level of expression of $n d h L$ which functioned in the concentration and transport of $\mathrm{Ci}[66,67]$, in roots and flowers might contribute to the transport of $\mathrm{Ci}$ to the leaves in Z. marina.

Most of the $n d h$ genes that encoded components in Subcomplex M, Subcomplex A and Subcomplex EDB were significantly induced or repressed during different light periods. Thus, the three subcomplexes could be the most sensitive parts involved in the activated of the NDH complex. More light responsive elements in pns/5 and $n d h M$ might related to the highly and continuously level of expression of these genes responded to light stress. In addition, the up regulated $n d h$ genes differed during the light exposure and dark recovery period. This suggested that there were two diverse responsive and regulatory mechanisms in the NDH-dependent PSI-CEF and chlororespiration.

\section{Conclusions}

In this study, we performed a systematic analysis of the identification, splicing, editing and pattern of expression of the Z. marina NDH complex. These results establish the foundation for further studies in the evolution, function and regulatory mechanism of the NDH complex.

\section{Methods}

\section{Plant materials and treatments}

Z. marina with intact rhizome systems were collected from subtidal seagrass beds in Yandunjiao, Rongcheng ( $\left.37^{\circ} 91^{\prime} \mathrm{N}, 120^{\circ} 73^{\prime} \mathrm{E}\right)$, Shandong Province, China, during their growth season. No specific permits were required to collect such samples. Samples were identified on the basis of their morphology by experienced taxonomists. Identifications were also confirmed by sequence similarity with the finished whole genome sequencing of $Z$. marina [33]. The specimen (HY202005) were deposited in the Herbarium of Ocean School of Yantai University, Shandong Province, China. Collection of plant materials complied with the institutional, national and international guidelines. Samples were cultured in an aquarium with seawater that was continuously aerated and renewed daily. Before experimentation, the plants were pre-cultivated for 3 days under $15^{\circ} \mathrm{C}$ with a photoperiod of $10 / 14 \mathrm{~h}$ (light/dark) in minimum saturation light intensity $\left(100 \mu \mathrm{mol}\right.$ photons $\left.\mathrm{m}^{-2} \mathrm{~s}^{-1}\right)$. 
The leaves obtained from dark-adapted overnight plants were exposed to $300 \mu \mathrm{mol}$ photons $\mathrm{m}^{-2} \mathrm{~s}^{-1}$, followed by recovery under darkness. For RT-PCR assays, the samples were collected after light exposure and recovery for $3 \mathrm{~h}$, respectively. For quantitative real time-PCR (qRT-PCR) assays, the samples were collected after light exposure and recovery for $10 \mathrm{~min}, 30 \mathrm{~min}, 1 \mathrm{~h}$ and $3 \mathrm{~h}$, respectively. The leaves under dark-adapted overnight were used as the control. Moreover, the roots, leaves, flowers, stems and rhizomes were collected at the flowering stage for tissue specific expression analyzes using the RT-PCR and qRT-PCR. There were three biological repeats for each sample.

\section{Identification of the Ndh subunits and sequence analysis}

BLASTP analyses were performed against the Z. marina database from the NCBI (https://www.ncbi.nlm.nih.gov/) and Phytozome (https://phytozome.jgi.doe.gov/pz/portal.html) databases using the $A$. thaliana Ndh protein sequences. The reannotated and misannotated genes were submitted to GenBank and can be retrieved with accession numbers MW051562 and MW051563. The number of amino acids, molecular weights and theoretical isoelectric points of Ndh subunits were attained by submitting protein sequences to the ExPasy website (http://web.expasy.org/protparam/). The conserved domains of each $n d h$ gene were confirmed using Pfam and SMART (http://smart.embl-heidelberg.de/). The exon-intron compositions of the ndh genes were constructed using DNAMAN software by comparing the cDNA with genomic sequences.

\section{Phylogenetic analysis}

Phylogenetic trees were generated from the amino acid alignments of both entire concatenated complex (31 subunits) and the individual Ndh subunits using MEGA5.0 with the following settings: Poisson model, pairwise deletion and 1000 bootstrap replications. Trees containing evolutionary model species in Monocots, Dicots, Amborellales, Lycophytes, Bryophytes, Charophyceae, Chlorophyta and Cyanobacteria were analyzed, using E. coli as an outgroup. The protein sequences of each species were acquired from the Phytozome and NCBI databases. All of the sequences were aligned using ClustalW2 [68]. The Interactive Tree of Life (https://itol.embl.de/) was used to visualize the trees.

\section{Structural characterization}

The motifs of Ndh subunits were identified using the MEME online program (http://meme.nbcr.net/meme/intro.html) with the following parameter sets: number of repetitions-any, maximum number of motifs - 20 and the optimum motif widths - 6 to 200 amino acid residues [69]. Trans-membrane helices in the Ndh subunits were predicted using TMHMM v2.0 [70]. The multiple sequence alignments and structure analysis were conducted with ESPript 3 in six species, including Thermosynechococcus elongatus BP-1, Z. mays, Sorghum bicolor, A. thaliana, Populus trichocarpa and Z. marina. [71].

\section{Nucleic acid isolation and cDNA synthesis}

Total DNA was extracted from 100 mg leaf tissue using the cetyltrimethylammonium bromide (CTAB) protocol [61]. Total RNA was isolated using a FastPure Plant Total RNA Isolation Kit (Vazyme, Nanjing, China). The quality of RNA was examined by electrophoresis on $1 \%$ agarose gel and quantified using NanoQuant (TECAN Group Ltd., Männedorf, Switzerland). After wiping off the residual DNA, the cDNA was synthesized with HiScript ${ }^{\circledR}$ II 1 st Strand cDNA Synthesis Kit (Vazyme) using $1 \mu \mathrm{g}$ of total RNA.

\section{PCR amplification and sequencing}

Primers were designed for polymerase chain reaction (PCR) and RT-PCR amplification using the DNA sequences obtained from GenBank (Additional file 8). DNA and cDNA templates were amplified using PrimeSTAR ${ }^{\circledR}$ Max DNA Polymerase (TaKaRa, Japan) with the following procedure: $98{ }^{\circ} \mathrm{C}$ for $10 \mathrm{~s}, 35$ cycles of $55^{\circ} \mathrm{C}$ for $10 \mathrm{~s}$ and $72{ }^{\circ} \mathrm{C}$ for $30 \mathrm{~s}$. The amplification products were separated on $1 \%$ agarose gel and purified using a FastPure Gel DNA Extraction Mini Kit (Vazyme) before Sanger sequencing.

\section{Analysis of splicing patterns}

The RT-PCR products of $n d h$ genes from five tissues and different light periods were visualized using a Gel Doc XR+ system (Bio-Rad, Hercules, CA, USA). The specific electrophoresis bands corresponded to differently spliced products. The possible protein isoforms were predicted by DNAMAN.

RNA editing analysis of chloroplast-encoded $n d h$ genes

To confirm the RNA editing sites in the $Z$. marinandh genes, the sequenced cDNA and DNA from different light periods were aligned using Vector NTI. The editing sites for S. polyrhiza [72], A.thaliana [73], Z. mays [74] and A. trichopoda [75] were obtained from respective publications.

\section{Analysis of gene expression}

QRT-PCR assays of the $n d h$ genes obtained from five tissues and different light periods were conducted on a Bio-Rad CFX96 Real Time PCR System with AceQ Universal SYBR qPCR Master Mix (Vazyme). The housekeeping gene gapdh from Z. marina was used as an internal control. The qRT-PCR was programmed as follows: $95^{\circ} \mathrm{C}$ for $10 \mathrm{~s}$, followed by 40 cycles of $56^{\circ} \mathrm{C}$ for $10 \mathrm{~s}$ and $72{ }^{\circ} \mathrm{C}$ for $30 \mathrm{~s}$. The qRT-PCR data were calculated using the $2^{-\triangle \Delta C T}$ method. Sequences of the primers used in qRT-PCR are described in Additional file 8. The tissue specific expression of $A$. thaliana was download as the publicly available RNA-Seq data in the CoNekT-Plants database (www.conekt.plant.tools). The RNA Seq of $Z$. marina under light stress was analyzed in our previously study [37]. The differentially expressed genes were selected according to $p<0.05$ and fold change $>1.3$ (for up-regulation) or fold change $<0.75$ (for down-regulation). Heatmaps were constructed using the transformed log2 (TPM+ 1) or log2 (FPKM + 1) values by TBtools software [76]. 
To obtain the possible cis-acting elements in the promoter regions of the $n d h$ genes, $1500 \mathrm{bp}$ genomic sequences upstream of the start code ATG were analyzed online using Plantcare (http://bioinformatics.psb.ugent.be/webtools/plantcare/html/).

\section{Statistical analysis}

Statistical analysis was analyzed using SPSS 22.0. All data were analyzed by one-way ANOVA and Tukey's tests with $p<0.05$ set to be statistically significant.

\section{List Of Abbreviations}

$\mathrm{NDH}$

NADH dehydrogenase-like; PSI-CEF:photosystem I cyclic electron flow; RT-PCR:reverse transcription-PCR; AA:amino acid; TM:transmembrane; AS:alternative splicing; IRs:inverted repeat regions; Ci:inorganic carbon; qRT-PCR:quantitative real time-PCR; CTAB:cetyltrimethylammonium bromide; PCR:polymerase chain reaction

\section{Declarations}

\section{Ethics approval and consent to participate}

Not applicable

\section{Consent for publication}

Not applicable.

\section{Availability of data and materials}

Individual sequences were submitted to GenBank (https://www.ncbi.nlm.nih.gov/genbank/) and can be retrieved with accession numbers MW051562 and MW051563. Voucher specimen (specimen number: HY202005) is available in Herbarium of Ocean School of Yantai University, Shandong Province, China.

\section{Competing interests}

The authors declare that they have no competing interests.

\section{Funding}

This research was funded by the National Natural Science Foundation of China (No.41376154) and the Yantai Municipal Key Research and Development Project (No. 2019XDHZ096). The funders had no role in the design of the study and collection, analysis, and interpretation of data and in writing the manuscript.

\section{Acknowledgments}

The authors thank to lab members for assistance.

\section{Author information}

\section{Affiliations}

${ }^{1}$ Ocean School, Yantai University, Yantai 264005, China

\section{Contributions}

MYM performed the experiments. MYM, MYZ analyzed the data. MMY wrote the manuscript. MMY and QSZ designed the study. All authors have read and approved the final manuscript.

\section{Corresponding author}

Correspondence to Quansheng Zhang.

\section{References}

1. Shikanai T: Cyclic electron transport around photosystem I: genetic approaches. Annu Rev Plant Biol. 2007;58:199-217.

2. Burrows P, Sazanov LA, Svab Z, Maliga P, Nixon PJ: Identification of a functional respiratory complex in chloroplasts through analysis of tobacco mutants containing disrupted plastid ndh genes. The EMBO journal. 1998;17(4):868-876.

3. Efremov RG, Baradaran R, Sazanov LA: The architecture of respiratory complex I. Nature. 2010;465(7297):441-445.

4. Suorsa M, Sirpiö S, Aro E-M: Towards Characterization of the Chloroplast NAD(P)H Dehydrogenase Complex. Molecular Plant. 2009;2(6):1127-1140.

5. Pan X, Cao D, Xie F, Xu F, Su X, Mi H, Zhang X, Li M: Structural basis for electron transport mechanism of complex I-like photosynthetic NAD(P)H dehydrogenase. Nature communications. 2020;11(1):610. 
6. Matsubayashi T, Wakasugi T, Shinozaki K, Yamaguchi-Shinozaki K, Kato A: Six chloroplast genes (ndhA-F) homologous to human mitochondrial genes encoding components of the respiratory chain NADH dehydrogenase are actively expressed: Determination of the splice sites in ndhA and ndhB premRNAs. Molecular \& General Genetics Mgg. 1987;210(3):385-393.

7. Ifuku K, Endo T, Shikanai T, Aro EM: Structure of the chloroplast NADH dehydrogenase-like complex: nomenclature for nuclear-encoded subunits. Plant \& cell physiology. 2011;52(9):1560-1568.

8. Ogawa T: A gene homologous to the subunit-2 gene of NADH dehydrogenase is essential to inorganic carbon transport of Synechocystis PCC6803. Proceedings of the National Academy of Sciences of the United States of America. 1991;88(10):4275-4279.

9. Shikanai T, Endo T, Hashimoto T, Yamada Y, Asada K, Yokota A: Directed disruption of the tobacco ndhB gene impairs cyclic electron flow around photosystem I. Proceedings of the National Academy of Sciences of the United States of America. 1998;95(16):9705-9709.

10. Essemine J, Qu M, Mi H, Zhu X-G: Response of Chloroplast NAD(P)H Dehydrogenase-Mediated Cyclic Electron Flow to a Shortage or Lack in FerredoxinQuinone Oxidoreductase-Dependent Pathway in Rice Following Short-Term Heat Stress. Front Plant Sci. 2016;7:383.

11. Horváth EM, Peter So, Joët T, Rumeau D, Cournac L, Horváth GV, Kavanagh TA, Schäfer C, Peltier G, Medgyesy P: Targeted inactivation of the plastid ndhB gene in tobacco results in an enhanced sensitivity of photosynthesis to moderate stomatal closure. Plant Physiol. 2000;123(4):1337-1350.

12. Wang P, Ye J, Shen Y, Mi H: The role of chloroplast NAD $(P) H$ dehydrogenase in protection of tobacco plant against heat stress. Sci China, $C$, Life Sci. 2006;49(4):311-321.

13. Yamori W, Sakata N, Suzuki Y, Shikanai T, Makino A: Cyclic electron flow around photosystem I via chloroplast NAD(P)H dehydrogenase (NDH) complex performs a significant physiological role during photosynthesis and plant growth at low temperature in rice. Plant Journal. 2011;68(6):966-976.

14. Li X-G, Duan W, Meng Q-W, Zou Q, Zhao S-J: The function of chloroplastic NAD(P)H dehydrogenase in tobacco during chilling stress under low irradiance. Plant \& cell physiology. 2004;45(1):103-108.

15. Tan Y, Zhang QS, Zhao W, Liu Z, Ma MY, Zhong MY, Wang MX: The highly efficient NDH-dependent photosystem I cyclic electron flow pathway in the marine angiosperm Zostera marina. Photosynthesis research. 2020;144(1):49-62.

16. Yang XQ, Zhang QS, Zhang D, Sheng ZT: Light intensity dependent photosynthetic electron transport in eelgrass (Zostera marina L.). Plant Physiology \& Biochemistry. 2017;113:168-176.

17. Bertelli CM, Unsworth RKF: Light Stress Responses by the Eelgrass, Zostera marina (L). Frontiers in Environmental Science. 2018;6:39-.

18. Wang C, Yamamoto H, Shikanai T: Role of cyclic electron transport around photosystem I in regulating proton motive force. Biochimica et biophysica acta. 2015;1847(9):931-938.

19. Shikanai T: Chloroplast NDH: A different enzyme with a structure similar to that of respiratory NADH dehydrogenase. Biochimica et biophysica acta. 2016;1857(7):1015-1022.

20. Ohyama K, Fukuzawa H, Kohchi T, Shirai H, Sano T, Sano S, Umesono K, Shiki Y, Takeuchi M, Chang Z: Chloroplast gene organization deduced from complete sequence of liverwort Marchantia polymorpha chloroplast DNA. Nature. 1986;322(6079):572-574.

21. Shinozaki, Ohme, Tanaka, Wakasugi, Sugiura: The complete nucleotide sequence of the tobacco chloroplast genome. Plant Molecular Biology Reporter. 1986;4(3):110-147.

22. Peltier G, Cournac L: Chlororespiration. Annu Rev Plant Biol. 2002;53:523-550.

23. Friedrich T, Weiss H: Modular evolution of the respiratory NADH:ubiquinone oxidoreductase and the origin of its modules. J Theor Biol. 1997;187(4):529540.

24. Ruhlman TA, Chang WJ, Chen JJ, Huang YT, Chan MT, Zhang J, Liao DC, Blazier JC, Jin X, Shih MC et al: NDH expression marks major transitions in plant evolution and reveals coordinate intracellular gene loss. BMC plant biology. 2015;15:100.

25. Ueda M, Kuniyoshi T, Yamamoto H, Sugimoto K, Ishizaki K, Kohchi T, Nishimura Y, Shikanai T: Composition and physiological function of the chloroplast NADH dehydrogenase-like complex in Marchantia polymorpha. The Plant journal : for cell and molecular biology. 2012;72(4):683-693.

26. Gao F, Zhao J, Wang X, Qin S, Wei L, Ma W: NdhV Is a Subunit of NADPH Dehydrogenase Essential for Cyclic Electron Transport in Synechocystis sp. Strain PCC 6803. Plant Physiol. 2016;170(2):752-760.

27. He Z, Zheng F, Wu Y, Li Q, Lv J, Fu P, Mi H: NDH-1L interacts with ferredoxin via the subunit NdhS in Thermosynechococcus elongatus. Photosynth Res. 2015;126(2-3):341-349.

28. Battchikova N, Wei L, Du L, Bersanini L, Aro EM, Ma W: Identification of novel Ssl0352 protein (NdhS), essential for efficient operation of cyclic electron transport around photosystem I, in NADPH:plastoquinone oxidoreductase (NDH-1) complexes of Synechocystis sp. PCC 6803. Journal of Biological Chemistry. 2011;286.

29. Weng M-L, Blazier JC, Govindu M, Jansen RK: Reconstruction of the ancestral plastid genome in Geraniaceae reveals a correlation between genome rearrangements, repeats, and nucleotide substitution rates. Mol Biol Evol. 2014;31(3):645-659.

30. Kim HT, Chase MW: Independent degradation in genes of the plastid ndh gene family in species of the orchid genus Cymbidium (Orchidaceae; Epidendroideae). PLoS ONE. 2017;12(11):e0187318.

31. Braukmann TWA, Kuzmina M, Stefanović S: Loss of all plastid ndh genes in Gnetales and conifers: extent and evolutionary significance for the seed plant phylogeny. Curr Genet. 2009;55(3):323-337.

32. Lin C-S, Chen JJW, Chiu C-C, Hsiao HCW, Yang C-J, Jin X-H, Leebens-Mack J, de Pamphilis CW, Huang Y-T, Yang L-H et al: Concomitant loss of NDH complex-related genes within chloroplast and nuclear genomes in some orchids. The Plant journal : for cell and molecular biology. 2017;90(5).

33. Olsen JL, Rouze P, Verhelst B, Lin YC, Bayer T, Collen J, Dattolo E, De Paoli E, Dittami S, Maumus F et al: The genome of the seagrass Zostera marina reveals angiosperm adaptation to the sea. Nature. 2016;530(7590):331-335.

Page $11 / 22$ 
34. Waycott M, Duarte CM, Carruthers TJ, Orth RJ, Dennison WC, Olyarnik S, Calladine A, Fourqurean JW, Heck KL, Jr., Hughes AR et al: Accelerating loss of seagrasses across the globe threatens coastal ecosystems. Proc Natl Acad Sci U S A. 2009;106(30):12377-12381.

35. Les DH, Cleland MA, Waycott M: Phylogenetic Studies in Alismatidae, II: Evolution of Marine Angiosperms (Seagrasses) and Hydrophily. Systematic Botany. 1997;22(3):443.

36. Iles WJD, Smith SY, Graham SW, Wilkin P, Mayo SJ: A well-supported phylogenetic framework for the monocot order Alismatales reveals multiple losses of the plastid NADH dehydrogenase complex and a strong long-branch effect. 2013:1-28.

37. Tan Y, Zhang QS, Zhao W, Liu Z, Ma MY, Zhong MY, Wang MX, Xu B: Chlororespiration Serves as Photoprotection for Photo-Inactivated Oxygen-Evolving Complex in Zostera marina, a Marine Angiosperm. Plant \& cell physiology. 2020.

38. Peng L, Yamamoto H, Shikanai T: Structure and biogenesis of the chloroplast NAD(P)H dehydrogenase complex. Biochimica et Biophysica Acta (BBA) Bioenergetics. 2011;1807(8):945-953.

39. Xing Q, Guo J: Characterization of the complete chloroplast genome of the seagrass Zostera marina using Illumina sequencing technology. Conservation Genetics Resources. 2017;10(3):419-422.

40. Peredo EL, King UM, Les DH: The Plastid Genome of Najas flexilis: Adaptation to Submersed Environments Is Accompanied by the Complete Loss of the NDH Complex in an Aquatic Angiosperm. PLoS ONE. 2013;8(7).

41. Lee H, Golicz AA, Bayer PE, Severn-Ellis AA, Chan CK, Batley J, Kendrick GA, Edwards D: Genomic comparison of two independent seagrass lineages reveals habitat-driven convergent evolution. Journal of experimental botany. 2018;69(15):3689-3702.

42. Fan X, Zhang J, Li W, Peng L: The NdhV subunit is required to stabilize the chloroplast NADH dehydrogenase-like complex in Arabidopsis. The Plant journal : for cell and molecular biology. 2015;82(2):221-231.

43. Ishikawa N, Takabayashi A, Ishida S, Hano Y, Endo T, Sato F: NDF6: a thylakoid protein specific to terrestrial plants is essential for activity of chloroplastic NAD(P)H dehydrogenase in Arabidopsis. Plant \& cell physiology. 2008;49(7):1066-1073.

44. Horvath, E. M: Targeted Inactivation of the Plastid ndhB Gene in Tobacco Results in an Enhanced Sensitivity of Photosynthesis to Moderate Stomatal Closure. Plant Physiol. 2000;123(4):1337-1349.

45. Kofer W, Koop HU, Wanner G, Steinmüller K: Mutagenesis of the genes encoding subunits A, C, H, I, J and K of the plastid NAD(P)H-plastoquinoneoxidoreductase in tobacco by polyethylene glycol-mediated plastome transformation. Mol Gen Genet. 1998;258(1-2):166-173.

46. Rumeau D, Becuwe-Linka N, Beyly A, Louwagie M, Garin J, Peltier G: New subunits NDH-M, -N, and -O, encoded by nuclear genes, are essential for plastid Ndh complex functioning in higher plants. The Plant cell. 2005;17(1):219-232.

47. Xiong A-S, Peng R-H, Zhuang J, Gao F, Zhu B, Fu X-Y, Xue Y, Jin X-F, Tian Y-S, Zhao W et al: Gene duplication, transfer, and evolution in the chloroplast genome. Biotechnology advances. 2009;27(4):340-347.

48. Wu C-S, Wang Y-N, Liu S-M, Chaw S-M: Chloroplast genome (cpDNA) of Cycas taitungensis and $56 \mathrm{cp}$ protein-coding genes of Gnetum parvifolium: insights into cpDNA evolution and phylogeny of extant seed plants. Mol Biol Evol. 2007;24(6):1366-1379.

49. Zhang Y, Ma J, Yang B, Li R, Zhu W, Sun L, Tian J, Zhang L: The complete chloroplast genome sequence of Taxus chinensis var. mairei (Taxaceae): loss of an inverted repeat region and comparative analysis with related species. Gene. 2014;540(2):201-209.

50. Qiao X, Li Q, Yin H, Qi K, Li L, Wang R, Zhang S, Paterson AH: Gene duplication and evolution in recurring polyploidization-diploidization cycles in plants. Genome Biol. 2019;20(1):38.

51. He X, Zhang J: Gene complexity and gene duplicability. Current biology : CB. 2005;15(11):1016-1021.

52. Schubert N, Colombo-Pallota MF, Enríquez S: Leaf and canopy scale characterization of the photoprotective response to high-light stress of the seagrass Thalassia testudinum. Limnology and Oceanography. 2015;60(1):286-302.

53. Reddy AS, Marquez Y, Kalyna M, Barta A: Complexity of the alternative splicing landscape in plants. The Plant cell. 2013;25(10):3657-3683.

54. Mockler FTC: Unproductive alternative splicing and nonsense mRNAs: A widespread phenomenon among plant circadian clock genes. Biology Direct. 2012.

55. Marquez Y, Brown JWS, Simpson C, Barta A, Kalyna M: Transcriptome survey reveals increased complexity of the alternative splicing landscape in Arabidopsis. Genome research. 2012;22(6):1184-1195.

56. Filichkin SA, Priest HD, Givan SA, Shen R, Bryant DW, Fox SE, Wong W-K, Mockler TC: Genome-wide mapping of alternative splicing in Arabidopsis thaliana. Genome research. 2010;20(1):45-58.

57. Staudt AC, Wenkel S: Regulation of protein function by 'microProteins'. EMBO reports. 2011;12(1):35-42.

58. Chateignerboutin A, Small I: Plant RNA editing. RNA Biology. 2010;7(2):213-219.

59. Uthaipaisanwong P, Chanprasert J, Shearman JR, Sangsrakru D, Yoocha T, Jomchai N, Jantasuriyarat C, Tragoonrung S, Tangphatsornruang S: Characterization of the chloroplast genome sequence of oil palm (Elaeis guineensis Jacq.). Gene. 2012;500(2):172-180.

60. Jobson RW, Qiu YL: Did RNA editing in plant organellar genomes originate under natural selection or through genetic drift. Biology Direct. 2008;3(1):43-43.

61. Chen H, Deng L, Jiang Y, Lu P, Yu J: RNA editing sites exist in protein-coding genes in the chloroplast genome of Cycas taitungensis. Journal of integrative plant biology. 2011;53(12):961-970.

62. Sirpiö S, Holmström M, Battchikova N, Aro E-M: AtCYP20-2 is an auxiliary protein of the chloroplast NAD(P)H dehydrogenase complex. FEBS Lett. 2009;583(14):2355-2358

63. Romano P, Gray J, Horton P, Luan S: Plant immunophilins: functional versatility beyond protein maturation. The New phytologist. 2005;166(3):753-769. 
64. Zhang Y, Li B, Xu Y, Li H, Li S, Zhang D, Mao Z, Guo S, Yang C, Weng Y et al: The cyclophilin CYP20-2 modulates the conformation of BRASSINAZOLERESISTANT1, which binds the promoter of FLOWERING LOCUS D to regulate flowering in Arabidopsis. The Plant cell. 2013;25(7):2504-2521.

65. Larkum AWD, Davey PA, Kuo J, Ralph PJ, Raven JA: Carbon-concentrating mechanisms in seagrasses. Journal of experimental botany. 2017;68(14):37733784 .

66. Zhang P, Battchikova N, Paakkarinen V, Katoh H, Iwai M, Ikeuchi M, Pakrasi HB, Ogawa T, Aro EM: Isolation, subunit composition and interaction of the NDH-1 complexes from Thermosynechococcus elongatus BP-1. The Biochemical journal. 2005;390(Pt 2):513-520.

67. Shimizu H, Peng L, Myouga F, Motohashi R, Shinozaki K, Shikanai T: CRR23/NdhL is a subunit of the chloroplast NAD(P)H dehydrogenase complex in Arabidopsis. Plant \& cell physiology. 2008;49(5):835-842.

68. Larkin MA, Blackshields G, Brown NP, Chenna R, Mcgettigan PA, Mcwilliam H, Valentin F, Wallace IM, Wilm A, Lopez R: Clustal W and Clustal X version 2.0. Bioinformatics. 2007;23(21):2947-2948.

69. Bailey TL, Boden M, Buske FA, Frith MC, Grant CE, Clementi L, Ren J, Li WW, Noble WS: MEME Suite: tools for motif discovery and searching. Nucleic Acids Res. 2009;37:202-208.

70. Krogh A, Larsson B, Von Heijne G, Sonnhammer ELL: Predicting transmembrane protein topology with a hidden markov model: application to complete genomes. Journal of Molecular Biology. 2001;305(3):567-580.

71. Robert X, Gouet P: Deciphering key features in protein structures with the new ENDscript server. Nucleic Acids Res. 2014;42:320-324.

72. Wang W, Zhang W, Wu Y, Maliga P, Messing J: RNA Editing in Chloroplasts of Spirodela polyrhiza, an Aquatic Monocotelydonous Species. PLoS ONE. 2015;10(10):e0140285.

73. Tillich M, Funk HT, Schmitz-Linneweber C, Poltnigg P, Sabater B, Martin M, Maier RM: Editing of plastid RNA in Arabidopsis thaliana ecotypes. The Plant journal : for cell and molecular biology. 2005;43(5):708-715.

74. Maier RM, Neckermann K, Igloi GL, Kossel H: Complete sequence of the maize chloroplast genome: gene content, hotspots of divergence and fine tuning of genetic information by transcript editing. Journal of Molecular Biology. 1995;251(5):614-628.

75. Hein A, Polsakiewicz M, Knoop V: Frequent chloroplast RNA editing in early-branching flowering plants: pilot studies on angiosperm-wide coexistence of editing sites and their nuclear specificity factors. BMC evolutionary biology. 2016;16:23.

76. Chen C, Chen H, Zhang Y, Thomas HR, Xia R: TBtools: An Integrative Toolkit Developed for Interactive Analyses of Big Biological Data. Molecular Plant. 2020;13(8).

\section{Figures}

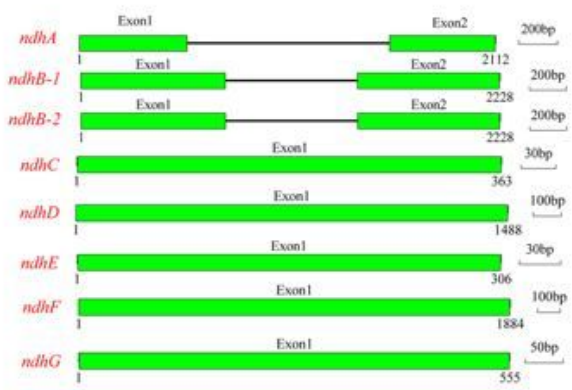

Subcomplex M

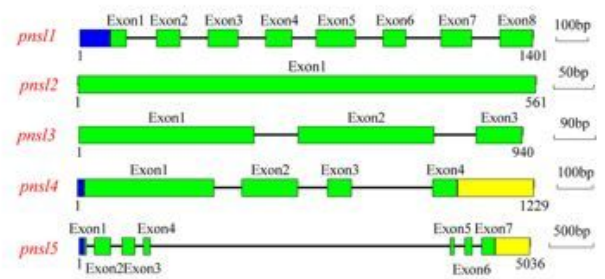

Subcomplex L

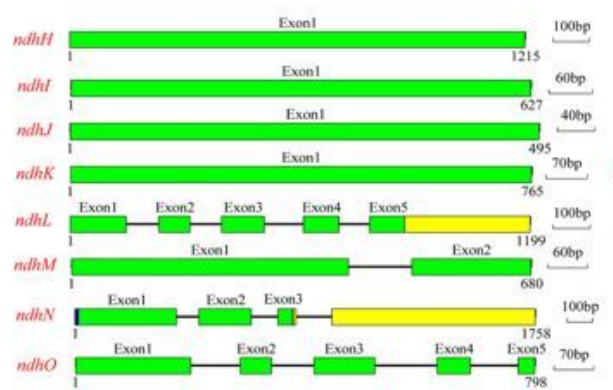

Subcomplex A

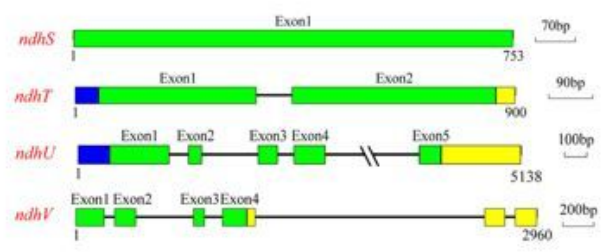

Subcomplex EDB

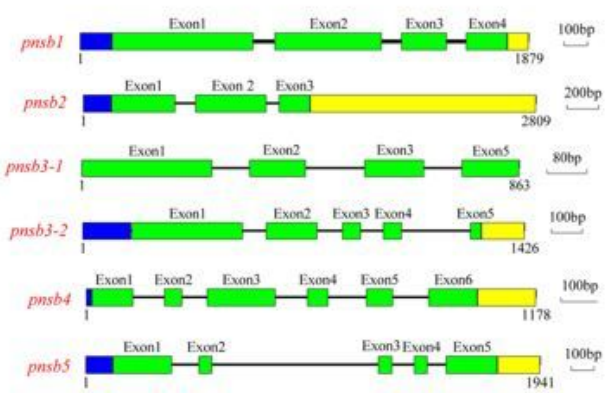

Subcomplex B

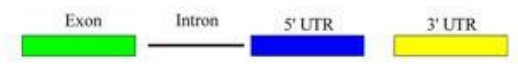

\section{Figure 1}

Gene model of ndh genes in Zostera marina. Blue boxes indicate untranslated 5' UTR, yellow boxes indicate 3' UTR, black lines indicate introns and green boxes indicate exons. The reannotated genes were highlighted by asterisk. The number at the bottom of each model represents gene length 


\section{Colored ranges}

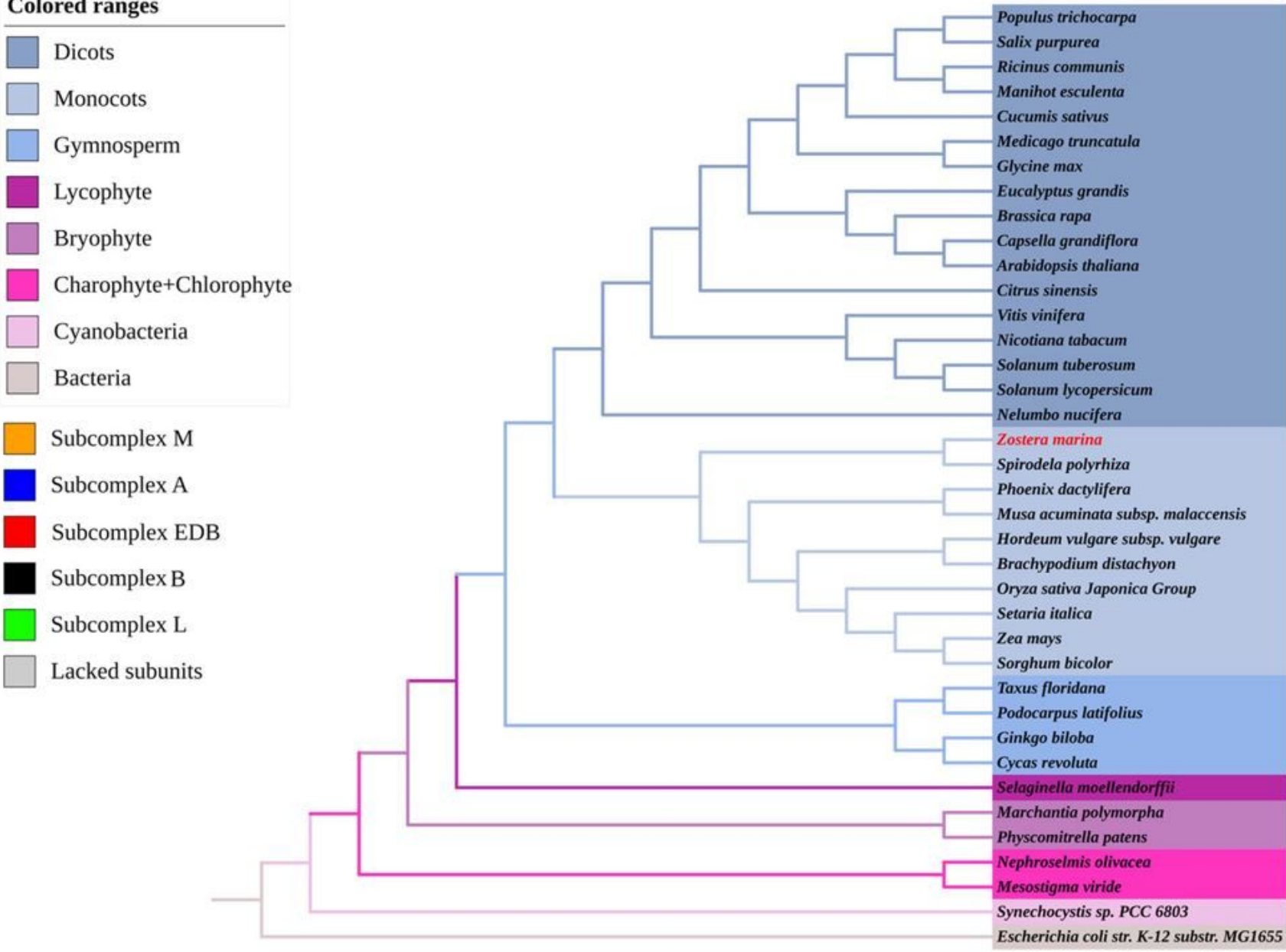

\section{Figure 2}

Phylogenetic relationship of NADH dehydrogenase-like (NDH) complex among Viridiplantae. The phylogenetic tree was constructed using concatenated amino acid sequences of 31 Ndh subunits by MEGA 5.0 software. Pie charts was divided into five part in which orange, blue, red, black and green represented Subcomplex M, Subcomplex A, Subcomplex EDB, Subcomplex B, Subcomplex L, respectively. Gray in pie charts indicating the lacking of Subcomplexes. 


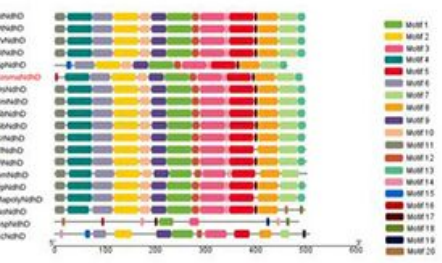

Fig. 3A
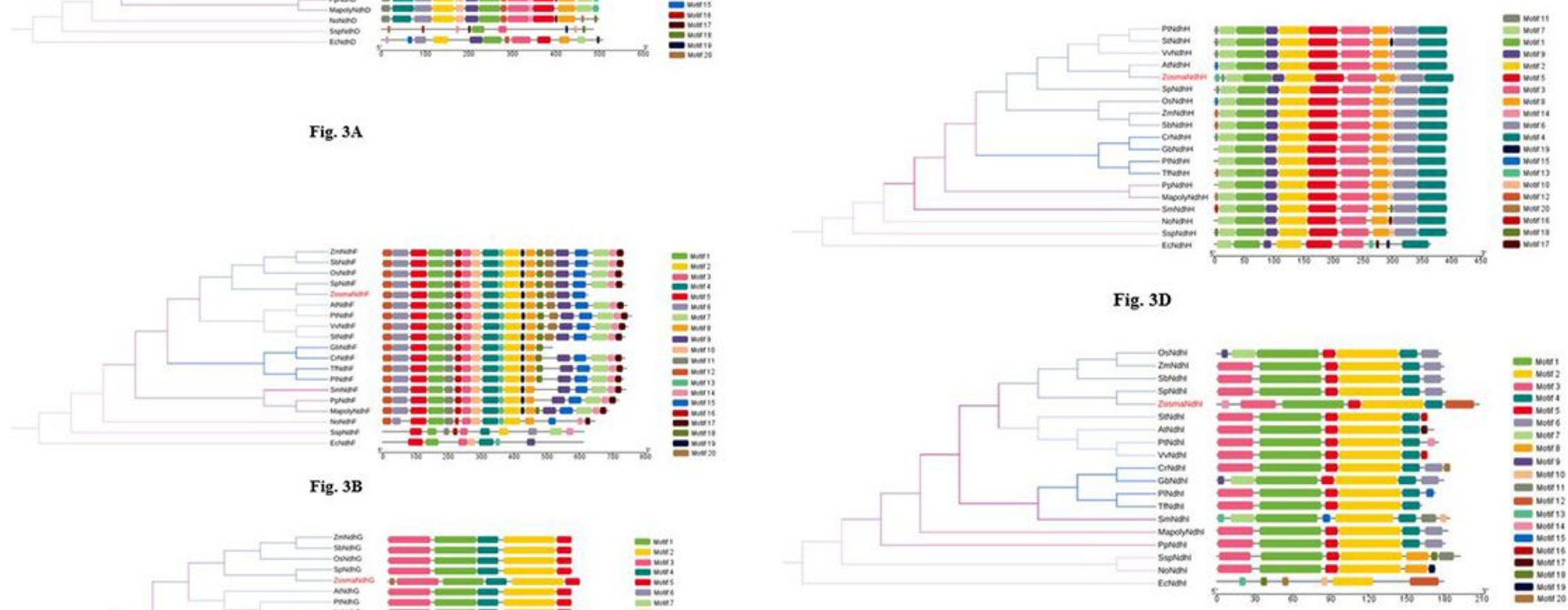

Fig. 3B

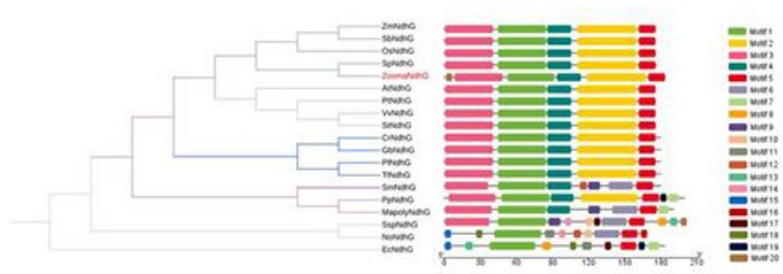

Fig. 3E

Fig. 3C

\section{Figure 3}

Phylogenetic trees and motif compositions of $\mathrm{NdhD}(\mathrm{A}), \mathrm{F}(\mathrm{B}), \mathrm{G}(\mathrm{C}), \mathrm{H}(\mathrm{D})$ and I (E) from nineteen different species. At, Arabidopsis thaliana; Cr, Cycas revoluta; Ec, Escherichia coli.; Gb, Ginkgo biloba; Mapoly, Marchantia polymorpha L.; No, Nephroselmis olivacea; Os, Oryza sativa Japonica; Pl, Podocarpus latifolius; Pp, Physcomitrella patens; Pt, Populus trichocarpa; Sb, Sorghum bicolor; Sm, Selaginella moellendorffii; Sp, Spirodela polyrhiza; Ssp, Synechocystis sp. PCC 6803; St, Solanum tuberosum; Tf, Taxus floridana; Vv, Vitis vinifera; Zm, Zea mays; Zosma, Zostera marina. The motifs numbered 1-20 indicate the motif composition of Ndh proteins, the scale at the bottom can be used as a reference of protein length. 


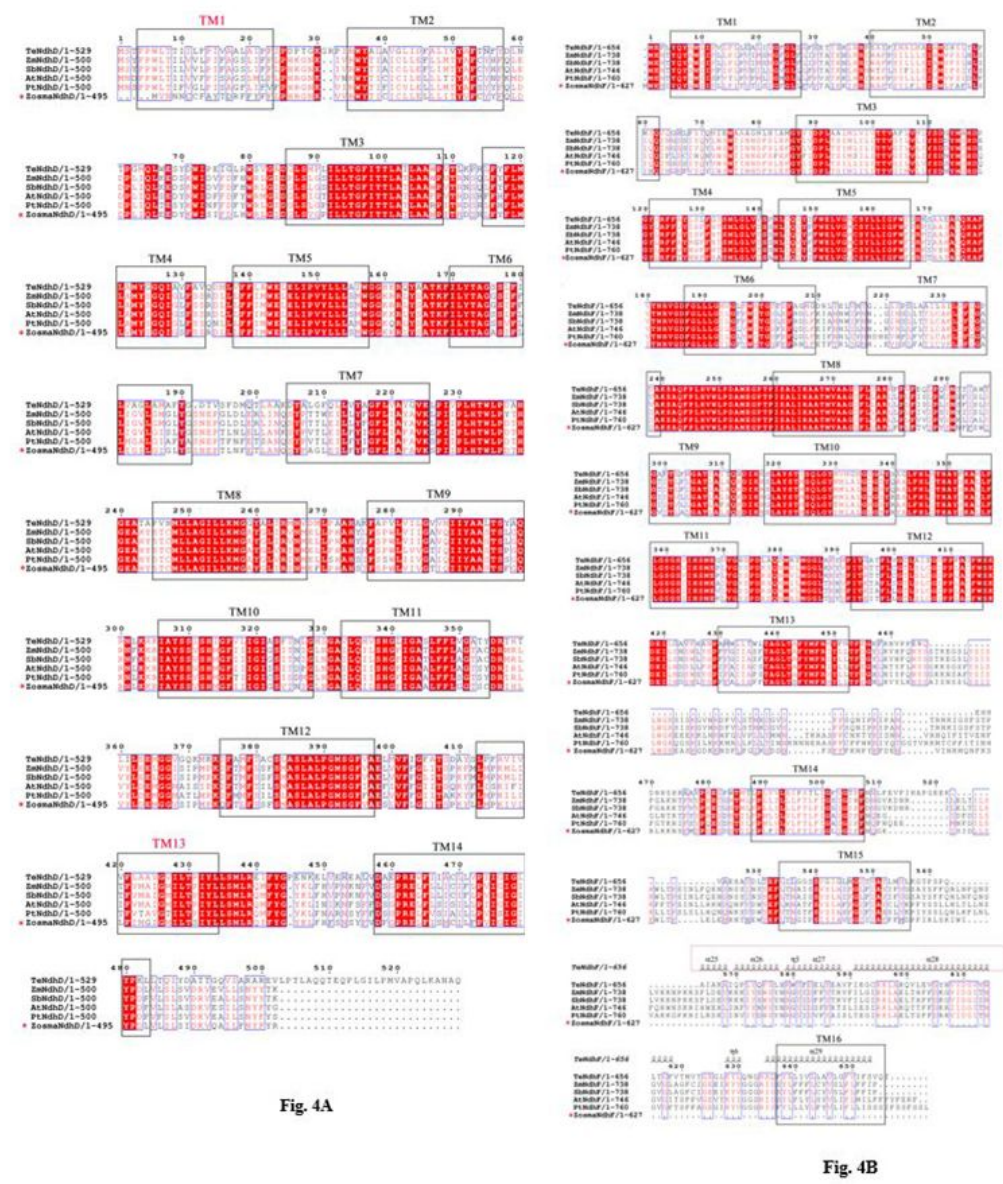

\section{Figure 4}

ClustalW amino acid alignment of the amino acid sequence of NdhD (A) and NdhF (B) from Z. marina with other five species. At, A. thaliana; Pt, P. trichocarpa; $\mathrm{Sb}$, S. bicolor; Te, Thermosynechococcus elongatus BP-1; Zm, Zea mays. The conserved transmembrane (TM) helices are indicated. The particular TM helix in Z. marina are labeled in red font. The long amphipathic helix in TM15 and TM16 were indicated above the sequences with red box. 

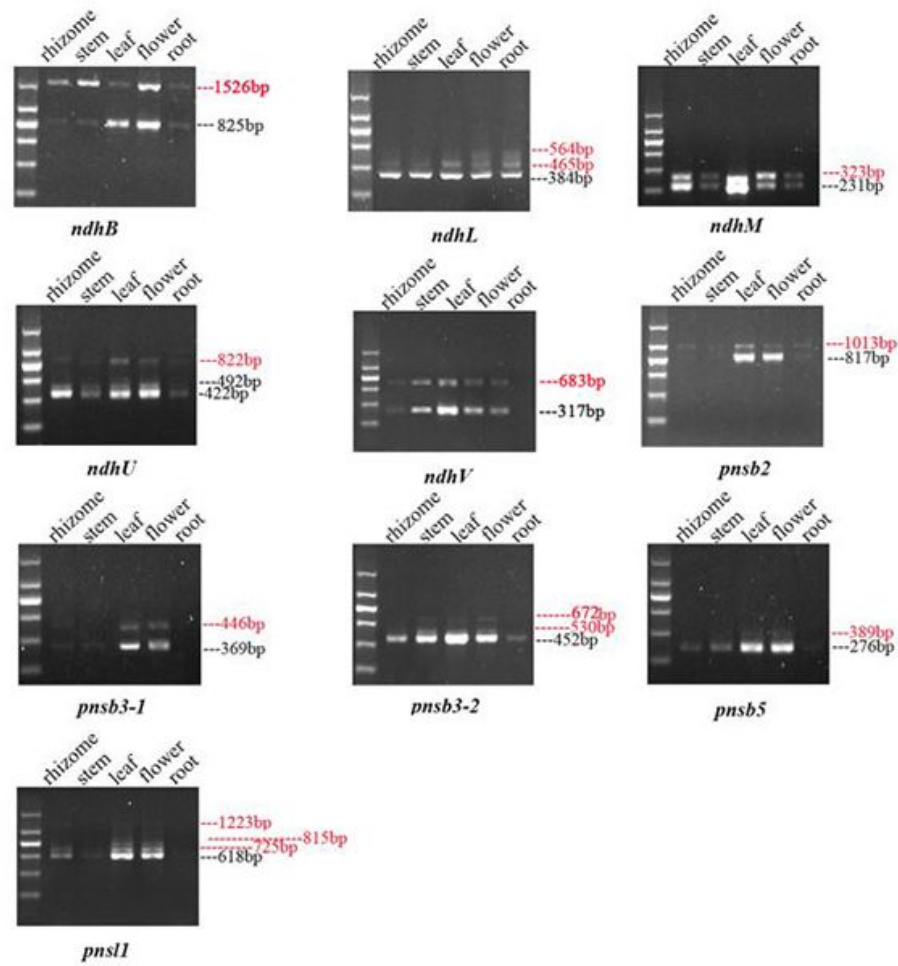
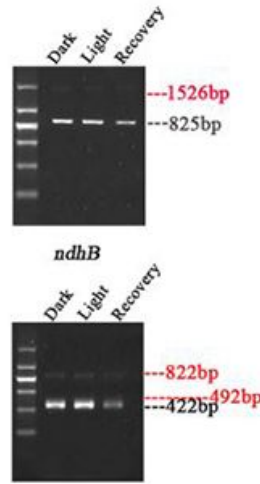

$n d b U$

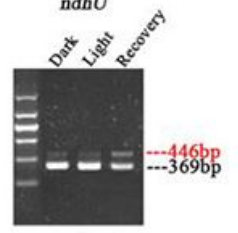

pnsb3-1

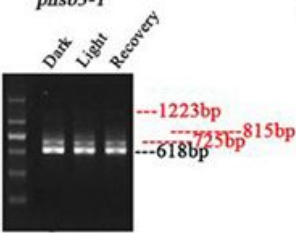

pnsII

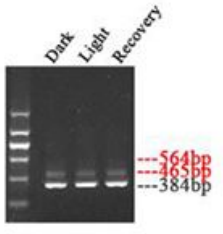

$n d h L$

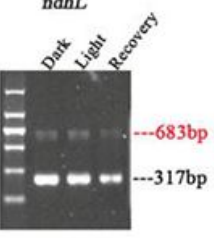

ndhV

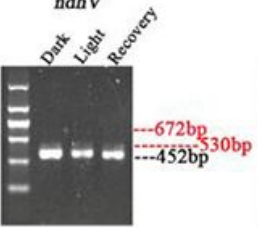

pnsb3-2
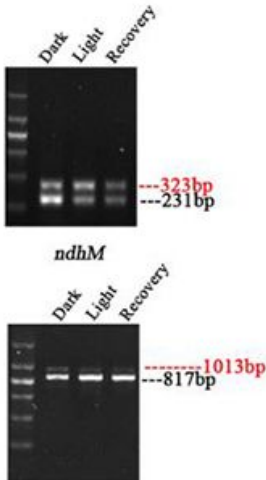

pnsb2

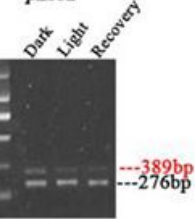

pnsb5

Fig. 5A

Fig. 5B

\section{Figure 5}

Splicing variants of the Z. marina ndh gene transcripts. Alternative splicing (AS) events in five tissues including rhizome, stem, leaf, flower and root (A). AS events in the period of light exposure and the subsequent dark recovery (B). The first lane left is $200 \mathrm{bp}$ ladder (200bp, 400bp, 600bp, 800bp, 1000bp, $1500 \mathrm{bp}$ ). AS transcripts are highlighted in red. The fundamental transcripts are labeled in black. Full-length gels are presented in Additional file 9 and 10. 

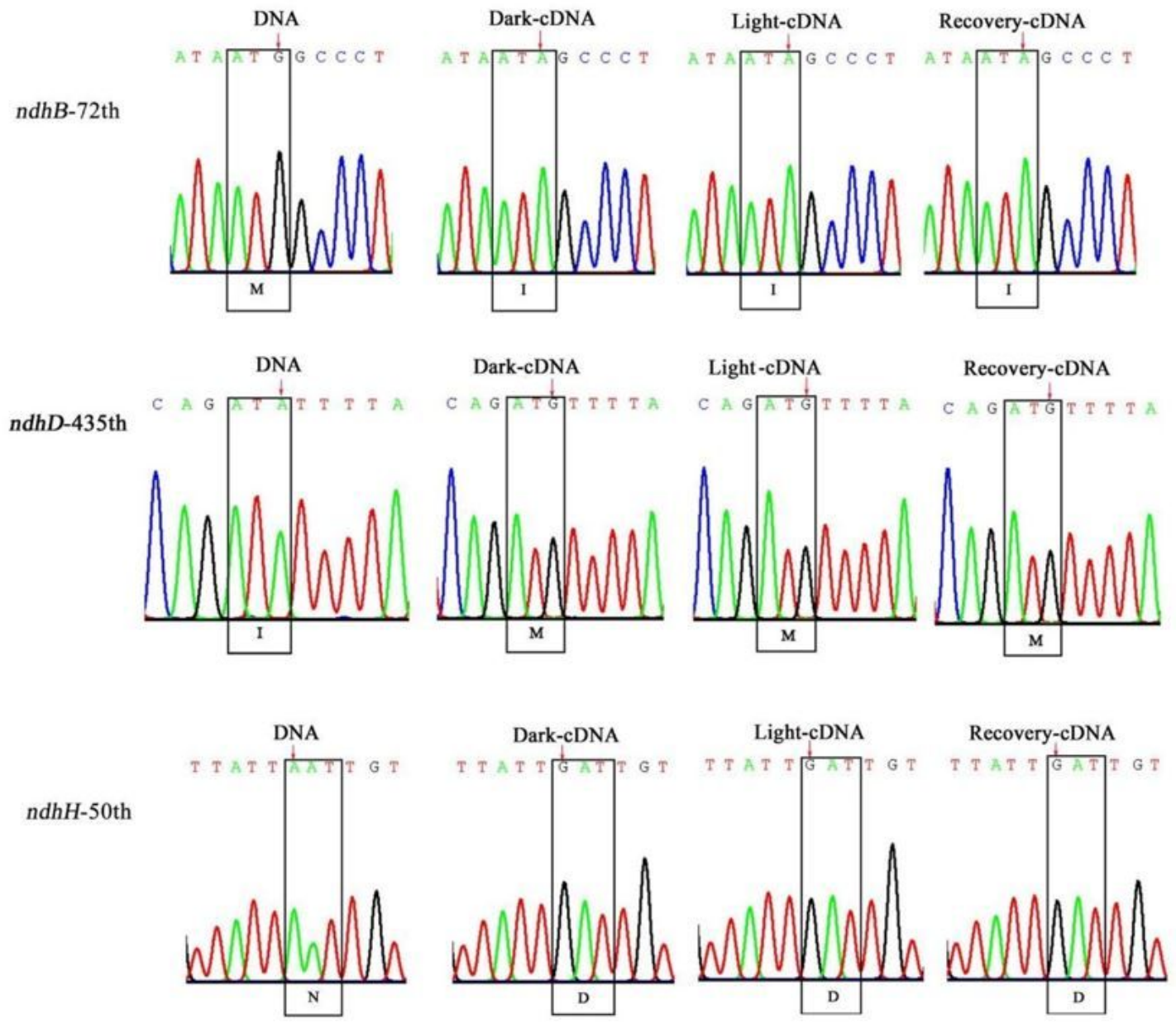

Figure 6

Gene model of the different isoforms of ndh genes occurring AS events. Blue boxes indicate untranslated 5' UTR, yellow boxes indicate 3' UTR, black lines indicate introns, green boxes indicate exons and intron retention is labeled red line. The number at the bottom of each model represents gene length. The length of amino acids is indicated after the gene models. 
Fig. 7A
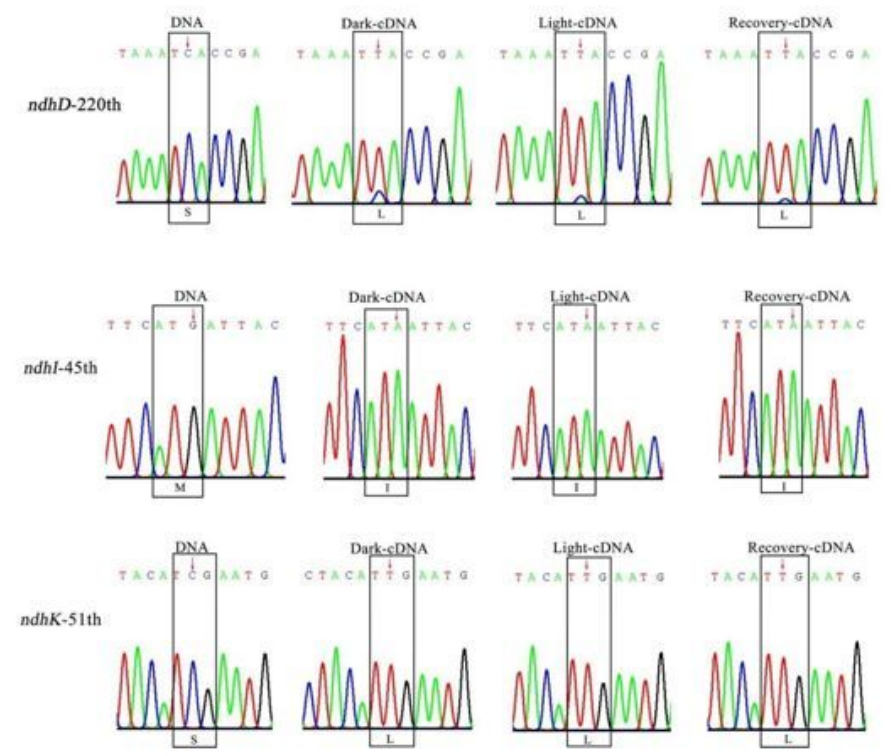

Fig. 7B

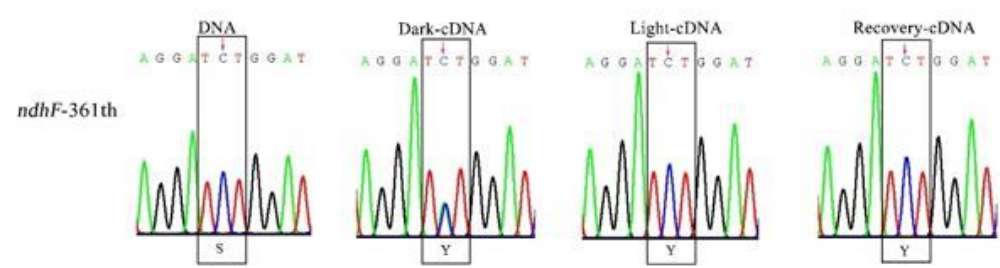

Fig. 7C

\section{Figure 7}

Gene model of the different isoforms of ndh genes occurring AS events. Blue boxes indicate untranslated 5' UTR, yellow boxes indicate 3' UTR, black lines indicate introns, green boxes indicate exons and intron retention is labeled red line. The number at the bottom of each model represents gene length. The length of amino acids is indicated after the gene models. Sequencing chromatograms of RNA editing sites that restored evolutionarily conserved amino acid sequences (A), generated lineage-specific residues in Z. marina (B) and influenced by light stress (C). The editing bases are indicated by arrows. The amino acids corresponding to the codons are indicated in the boxes. 


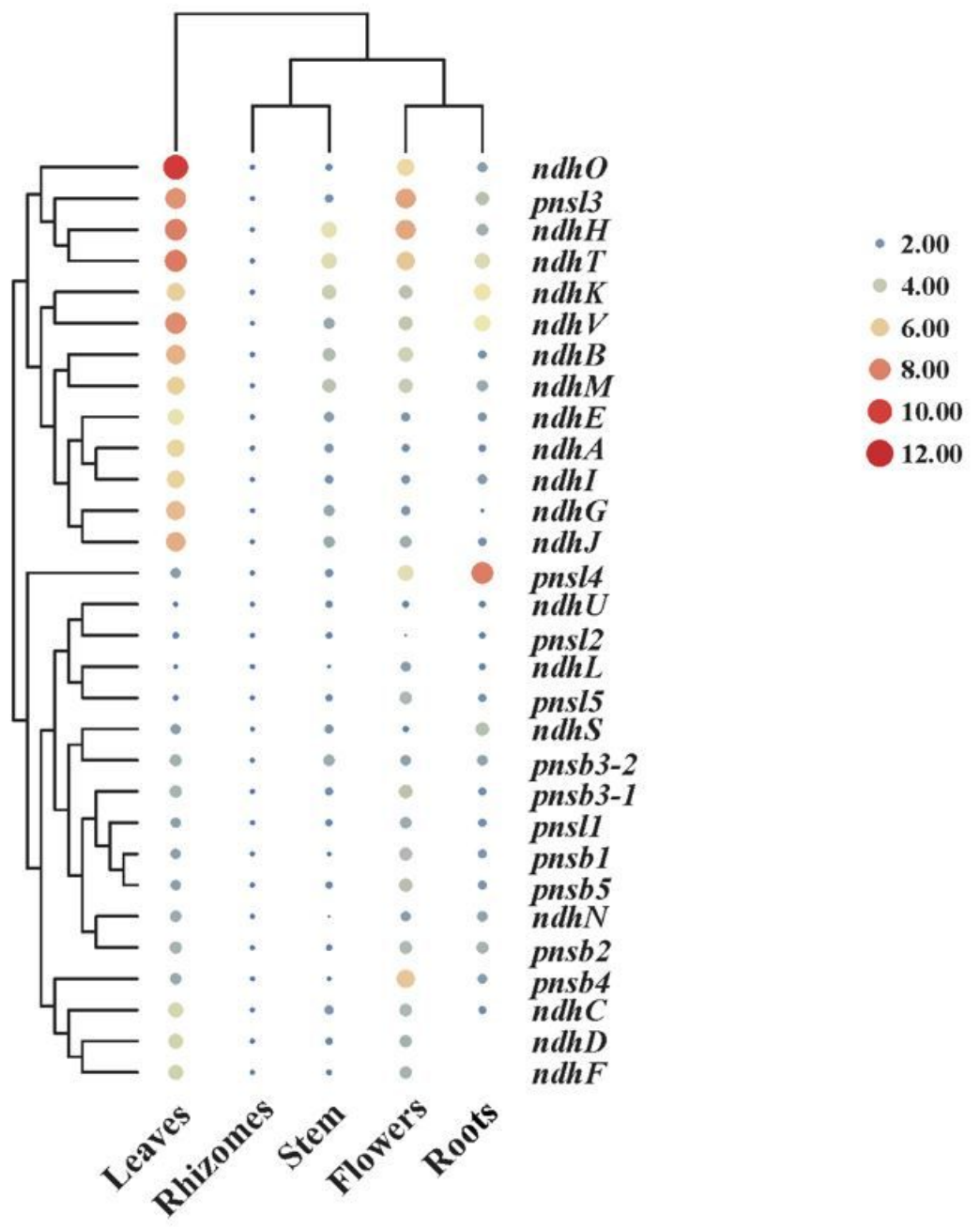

Figure 8

Patterns of expression of ndh genes in five tissues were analyzed by quantitative real time-PCR (qRT-PCR). To calculate the relative expression level, the expression of ndh gene in rhizomes was set as control. Gapdh was used as reference gene. Relative level of expression was transformed by log2 and can assessed by the size and color of the circle. 


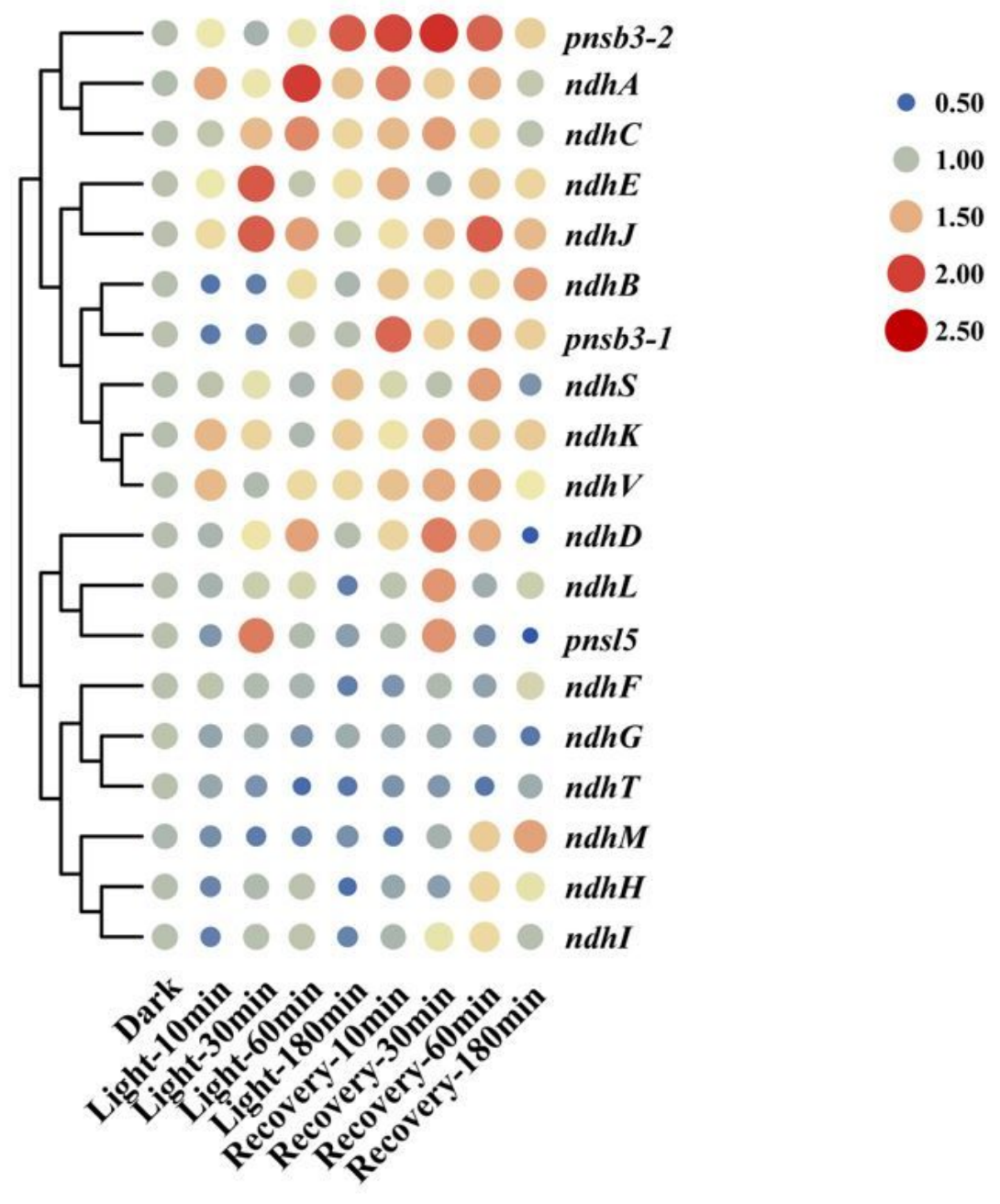

Figure 9

Patterns of expression of ndh genes in the period of light exposure and the subsequent recovery were analyzed by qRT-PCR. To calculate the relative expression level, the expression of ndh gene under dark condition was set as control. Gapdh was used as reference gene. Relative level of expression was transformed by log2 and can assessed by the size and color of the circle. 


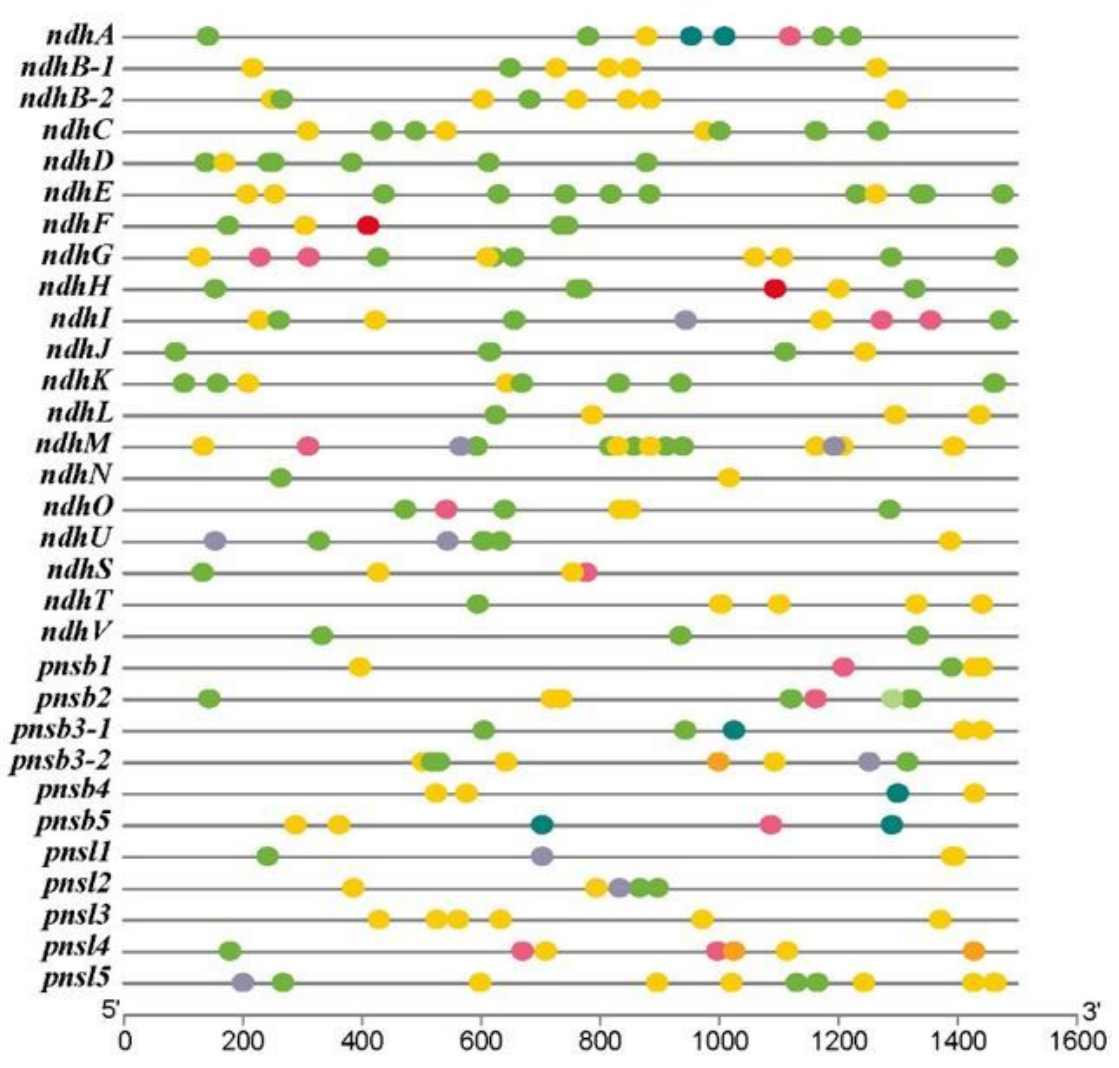

TATA-box

light responsive

salicylic acid responsive

CAAT-box

wound-responsive element

defense and stress responsive

auxin-responsive

abscisic acid responsive

\section{Figure 10}

Predicted cis-elements in ndh genes promoters. Promoter sequences ( $-1500 \mathrm{bp})$ of $31 \mathrm{ndh}$ genes are detected by PlantCARE. The upstream length to the translational start site can refer to the scale at the bottom.

\section{Supplementary Files}

This is a list of supplementary files associated with this preprint. Click to download.

- Additionalfile1.docx

- Additionalfile10.docx

- Additionalfile2.docx

- Additionalfile3.docx

- Additionalfile4.docx

- Additionalfile5.docx

- Extra.JPG

- Additionalfile6.docx

- Additionalfile7.docx

- Additionalfile8.docx

- Additionalfile9.docx 